\title{
Ferroptosis Holds Novel Promise in Treatment of Cancer Mediated by Non-coding RNAs
}

\begin{abstract}
Yuan Zhi',2, Ling Gao ${ }^{3,4}$, Baisheng Wang ${ }^{5}$, Wenhao Ren ${ }^{3,4}$, Kristina Xiao Liang ${ }^{6,7 *}$ and Keqian Zhi3,4*

${ }^{1}$ Department of Oral and Maxillofacial Surgery, The Second Xiangya Hospital, Central South University, Changsha, China, ${ }^{2}$ Xiangya School of Stomatology, Central South University, Changsha, China, ${ }^{3}$ Department of Oral and Maxillofacial Surgery, The Affiliated Hospital of Qingdao University, Qingdao, China, ${ }^{4}$ Key Lab of Oral Clinical Medicine, The Affiliated Hospital of Qingdao University, Qingdao, China, ${ }^{5}$ Department of Oral and Maxillofacial Surgery, Xiangya Stomatological Hospital and School of Stomatology, Central South University, Changsha, China, ${ }^{6}$ Neuro-SysMed, Center of Excellence for Clinical Research in Neurological Diseases, Haukeland University Hospital, Bergen, Norway, ${ }^{7}$ Department of Clinical Medicine (K1), University of Bergen, Bergen, Norway
\end{abstract}

OPEN ACCESS

Edited by:

Simone Patergnani,

University of Ferrara, Italy

Reviewed by:

Hamed Mirzaei,

Kashan University of Medical

Sciences, Iran

Yi Zhen Deng,

South China Agricultural University,

China

Bernhard Biersack,

University of Bayreuth, Germany

*Correspondence:

Kristina Xiao Liang xiao.liang@uib.no

Keqian Zhi

zhikeqian@sina.com zhikeqianqd@qdu.edu.cn

Specialty section:

This article was submitted to Molecular and Cellular Oncology, a section of the journal Frontiers in Cell and Developmental

Biology

Received: 28 March 2021

Accepted: 21 May 2021

Published: 21 June 2021

Citation:

Zhi Y, Gao L, Wang B, Ren W Liang KX and Zhi K (2021) Ferroptosis Holds Novel Promise in Treatment of Cancer Mediated by Non-coding

RNAs.

Front. Cell Dev. Biol. 9:686906. doi: 10.3389/fcell.2021.686906
Ferroptosis is a newly identified form of regulated cell death that is associated with iron metabolism and oxidative stress. As a physiological mechanism, ferroptosis selectively removes cancer cells by regulating the expression of vital chemical molecules. Current findings on regulation of ferroptosis have largely focused on the function of non-coding RNAs (ncRNAs), especially microRNAs (miRNAs), in mediating ferroptotic cell death, while the sponging effect of circular RNAs (circRNAs) has not been widely studied. In this review, we discuss the molecular regulation of ferroptosis and highlight the value of circRNAs in controlling ferroptosis and carcinogenesis. Herein, we deliberate future role of this emerging form of regulated cell death in cancer therapeutics and predict the progression and prognosis of oncogenesis in future clinical therapy.

Keywords: ferroptosis, lipid peroxidation, miRNAs, circRNAs, multiple drug resistance, cancer therapy

\section{INTRODUCTION}

Cell death is an irreversible mechanism that is associated with metabolism of the internal environment within the eukaryon in order to maintain cellular homeostasis and development in mammals. Recently, ferroptosis has been identified as a type of non-apoptotic cell death (Dixon et al., 2012), leading to a loss of cells without caspase activity and receptor-interacting protein

\footnotetext{
Abbreviations: a-KG, a-ketoglutarate; AKT, protein kinase B; ALOX12, arachidonate 12-lipoxygenase; ALKBH5, AlkB Homolog 5; ARE, antioxidant responsive element; AURKA, aurora kinase A; CBS, Cystathionine- $\beta$-synthase; circRNA, circular RNA; DAT, dihydroartemisinin; ELAVL1, embryonic lethal abnormal vision-like RNA-binding protein; ERK, extracellular regulated protein kinases; ESCC, esophageal squamous cell carcinoma; Fe(II), ferrous iron; FIN, ferroptosisinducing agents; $\gamma$-GCS, glutamyl cysteine synthetase; Gln, glutamine; GLS2, glutaminase 2; Glu, glutamate; GOT1, glutamic-oxaloacetic transaminase 1; GPX2, glutathione peroxidase 2; GPX4, glutathione peroxidase 4; GSH, glutathione; GSR, glutathione reductase; GSSG, glutathione oxidized; IRI, ischemia reperfusion injury; let-7, lethal-7; lin-4, lineage defective 4; lncRNA, long non-coding RNA; MDR, multiple drug resistance; MEK, mitogen-activated protein kinase kinase; miRNA, micro RNA; mTOR, mammalian target of rapamycin; MT-1G, metallothionein 1G; ncRNA, non-coding RNA; Nrf2, nuclear factor erythroid 2-related factor 2; NSCLC, non-small cell lung carcinoma; OSCC, oral squamous cell carcinoma; PDLSC, periodontal ligament stem cells; PIK3CD, phosphatidylinositol-4,5-bisphosphate 3-kinase catalytic subunit delta; PUFA, polyunsaturated fatty acid; RIPK1, receptor interacting protein 1 kinase; ROS, reactive oxygen species; RSL3, Rasselective lethal small molecule 3; SAT1, spermidine/spermine N1-acetyltransferase1; SLC1A5, solute carrier family 1 member 5; SLC7A11, solute carrier family 7 member 11; SLC38A1, solute carrier family 38 member 1; TfR1, transferrin receptor 1.
} 
1 (RIPK1) kinase activity (Yagoda et al., 2007; Yang and Stockwell, 2008). Different from other types of cell death at the biochemical, morphological, and genetic levels, ferroptosis is characterized by an absence of apoptosis, its dependence on iron, and its ability to disrupt intracellular redox balance (Zuo et al., 2020). Once initiated, ferroptosis causes the cell cytoplasm to become round and detached and causes damage to the mitochondria, including condensed mitochondrial membrane densities, reduced or vanished mitochondria crista, and rupturing of the outer mitochondrial membrane (Xie et al., 2016). Meanwhile, ferroptosis is able to reach a dynamic equilibrium in cell metabolism under physiological conditions. On the other hand, ferroptosis presents itself across many diseases, including heart disease, brain damage, and Alzheimer disease when the equilibrium is broken (Stockwell et al., 2017). Additionally, ferroptosis has been highlighted as a powerful weapon against cancers according to an increasing number of studies. Therapies that rely on ferroptosis have also been applied to the clinic, as several cancers are particularly vulnerable to ferroptotic inducers (e.g., erastin, RSL3) and chemotherapeutic agents (e.g., sulfasalazine, sorafenib). Therefore, it is necessary to determine this newly discovered type of cell death, as well as its connection to cancer.

Non-coding RNAs (ncRNAs) used to be considered junk molecules, but have recently incite considerable interest and new insights (Palazzo and Lee, 2015) due to their essential characteristics in gene expression and translational regulation (Nigita et al., 2019). MiRNAs (miRNAs) and long non-coding RNAs (lncRNAs), the two major members of ncRNAs, have vital roles in gene expression and physiological processes (Asma et al., 2019; Javid et al., 2021). It has been reported that similar regulatory methods of miRNAs and lncRNAs also exist in ferroptosis modulation (Mou et al., 2019). As a special ncRNA with a unique structure, circular RNAs (circRNAs) have been proven to control the regulatory processes of ncRNAs as either miRNA sponges or by direct inhibition (Hansen et al., 2013; Memczak et al., 2013). However, the knowledge of the rare and controversial circRNAs in regulating ferroptosis among diverse pathological conditions has not yet been well elucidated. Herein, it is of high value to highlight the characteristics, functions, and mechanisms of circRNAs in different cancer cells. We also provide an overview of recent discoveries of the role of circRNAs in mediating ferroptosis and future application of circRNAs as novel therapeutic targets.

\section{DEFINITION AND PHYSIOLOGICAL EFFECTS OF FERROPTOSIS}

Ferroptosis refers to a novel form of non-apoptotic cell death. The hallmarks of ferroptosis progression include lipid peroxidation, iron dependence, and inhibition of GPX4dependent antioxidative systems, leading to a lethal accumulation of lipid reactive oxygen species (ROS), which eventually leads to cell death. On the contrary, iron chelators, antioxidative enzymes, and depletion of polyunsaturated fatty acids (PUFAs) prevents cells from ferroptosis. Additionally, accumulation of lethal lipid
ROS has a significant function in numerous diseases, including tumorigenesis, neurological diseases, ischemia reperfusion injury (IRI), renal failure, and hematological system diseases. Emerging evidence has demonstrated that the accumulation of iron in pathological regions is a symptom of specific degenerative diseases (Ward et al., 2014). Moreover, previous studies have shown the anti-oncogenic potential of ferroptosis in neoplastic diseases, whereas ferroptosis can eliminate malignant cells with insufficient essential nutrients (Stockwell et al., 2017). Whether ferroptosis can contribute to the pathogenesis of other diseases is not yet clear, though it has been suggested that ferroptosis is a physiological process that widely occurs in mammals, rather than a pathological or organ-specific process. Therefore, future investigations need to be conducted to distinguish the triggers of ferroptotic cell death under physiological or pathological conditions.

\section{BIOCHEMICAL REGULATION OF FERROPTOSIS}

The initiation and execution of ferroptosis relies on the intersection of amino acid, lipid and iron metabolism (Yagoda et al., 2007). In other words, ferroptosis sensitivity is controlled by several metabolic and biochemical pathways and processes, including cysteine metabolism, glutathione metabolism and radical homeostasis (Figure 1).

\section{Cysteine Metabolism}

Cystine is a disulfide congener of cysteine. Cystine import is driven by system Xc- (Liu N. et al., 2020) with glutamate (Glu) export. As for cellular cysteine, there are two main pathways for cysteine compensation. One pathway is the transmembrane import, which is a rate-limiting process of cysteine accumulation (Bannai and Tateishi, 1986) that is indispensable for glutathione (GSH) biosynthesis and GPX4 bioactivity (Goji et al., 2017). The other is transsulfuration pathway, which acts as a pivotal method to supplement cellular cysteine. Methionine, generated from decomposition of dietary proteins through folate metabolism (Robinson et al., 2018), is an important substrate of transsulfuration pathway and is exerted to synthesize homocysteine catalyzed by ATPdependent methionine denosyltransferase-induced reaction. In conclusion, these two pathways have jointly ensured the stability of cellular cysteine metabolism and further maintain GSH homeostasis, which is involved in the antioxidative efficacy of radical scavenging.

\section{Glutathione Metabolism}

Glutamine (Gln), a non-essential amino acid, is the most abundant amino acid within the circulatory system of human body. Sufficient cellular Gln is crucial for compensation of GSH, which further enhances the scavenging efficacy to attenuate cellular damage caused by ferroptosis. GPX4 is an essential enzyme that enhances the ferroptosis resistance by transforming lipid hydroperoxides (L-OOH) into the alcohol forms (L-OH), and further maintain cellular redox equilibrium. Besides, nuclear 


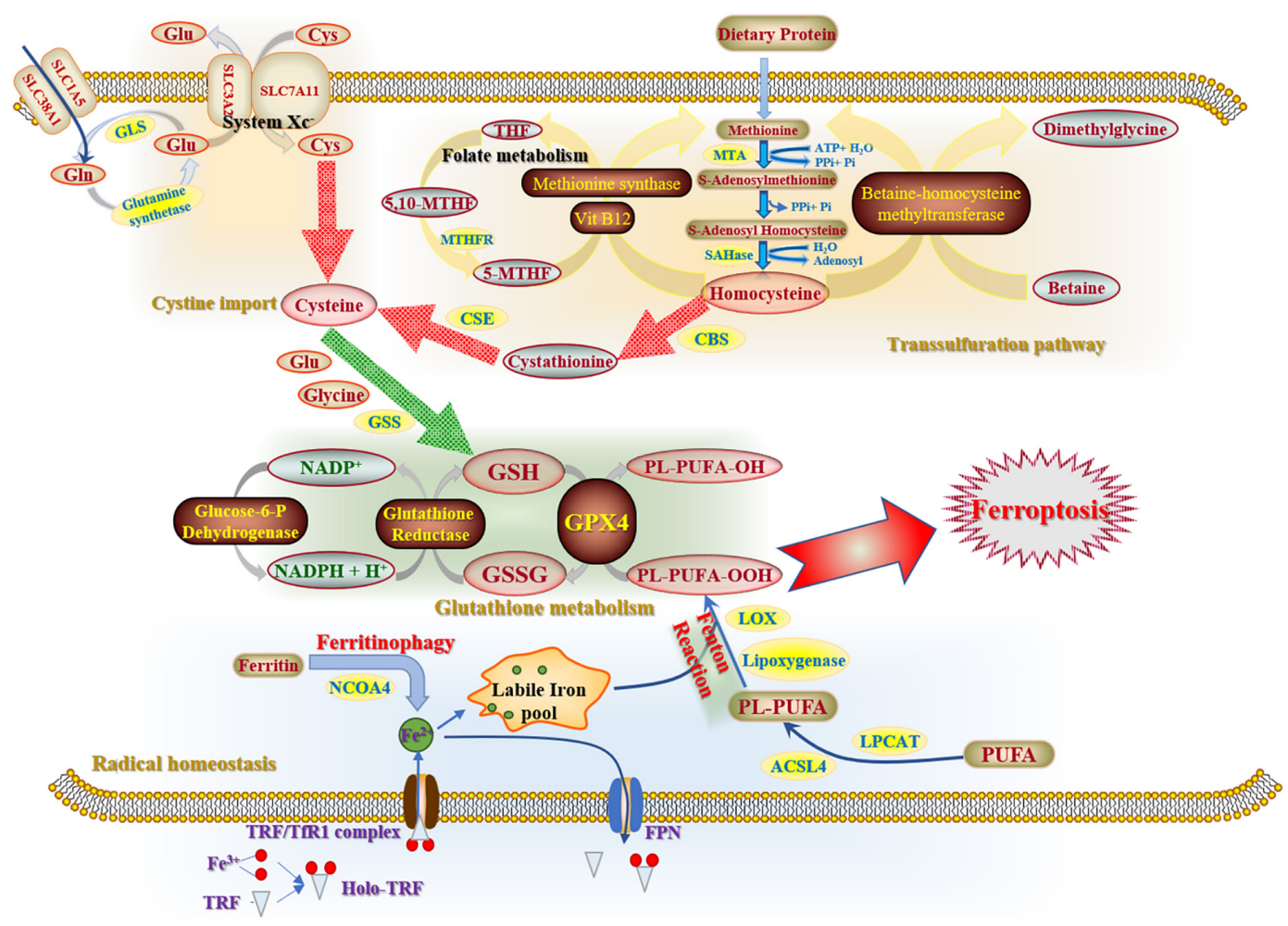

FIGURE 1 | Three main components of ferroptosis mechanisms. Cysteine metabolism, consisting of cystine import and transsulfutation pathway, refers to a compensation method of cellular cysteine that contributes to the biofunction of glutathione (GSH) cycle in cytoplasm. As the key factor of antioxidative system, glutathione metabolism removes excessive ROS with the participation of GPX4 and NADPH. Radical homeostasis is the essential link to exacerbate cell destroy. Labile iron pool is accumulated excessively as a substrate of Fenton reaction for ROS generation by the uptake of ferrous iron and degradation of ferritin.

factor erythroid 2-related factor 2 (Nrf2), another pivotal enzyme involved in the cellular antioxidative system, has a positive effect on GSH metabolism by upregulating the radical-scavenging enzyme $\gamma$-glutamyl cysteine synthetase $(\gamma$-GCS) (Kobayashi and Yamamoto, 2006) and mediating levels of glutathione reductase (GSR). Hence, there is a significant correlation between Nrf2 and GSH metabolism in order to set up resistance to lipid peroxidation (Dayalan et al., 2015).

\section{Radical Homeostasis}

Radical homeostasis is reliant on both iron and ROS metabolism. In iron metabolism, once Fe (II) has combined with transferrin, the transferrin receptor 1 (TfR1), a transmembrane glycoprotein, will internalize this complex and release it into the cytoplasm. The transferrin-bound iron will be stored into a non-toxic form inside ferritins. The process of ferritin's sequestration and degradation is termed as ferritinophagy, during which the labile iron pool can be enriched by degrading mitochondrial heme and ferritins (Mancias et al., 2014). Ferroportin is the only transmembrane protein that is able to export cellular iron (Drakesmith et al., 2015). ROS, a product of lipid peroxidation through the Fenton Reaction, is regarded as a lethal oxidizing agent of cellular oxidative stress. Additionally, polyunsaturated fatty acids (PUFAs) also have an impact on the process of redox equilibrium and sensitivity of cell death. It has been reported that the
$\mathrm{Ca}^{2+}$-independent phospholipase $\mathrm{A}_{2} \beta$ (iPLA2 $\beta$ ) can attenuate ferroptosis by hydrolyzing cellular peroxidized phospholipids (Sun et al., 2021).

\section{FERROPTOSIS, POTENTIAL VALUE IN NEOPLASTIC DISEASES}

The sensitivity of neoplastic diseases to ferroptosis is highly valued for underlying therapeutic strategies. Ferroptosis may serve as an inhibitory factor for carcinogenesis as neoplastic cells are vulnerable to increased levels of Fe (II) and cellular lipid peroxides (Stockwell et al., 2017). Conversely, due to the upregulation of ferroportin, decreased levels of cellular Fe (II) is a potential defense of cancer cells against ferroptosis to establish a favorable tumor microenvironment for colonization and proliferation (Geng et al., 2018; Bao et al., 2020). Therefore, we propose that ferroptosis may be exerted as a novel approach of tumor suppression due to its inhibition against cell proliferation, tumor migration and invasion.

Classically, inducers of ferroptosis are able to modulate the progression of cell death either directly or indirectly. Erastin is able to selectively inhibit System Xc- antitransport, and decrease cystine uptake in several tumor cell lines (e.g., HT1080, Calu-1, A-673, Panc-1) (Choi, 1988; Murphy et al., 1989; 
Zuo et al., 2020). In addition, Ferroptosis-inducing agents 56 (FIN56) can promote GPX4 degradation and exacerbate lipid peroxidation in cancer cells (Shimada et al., 2016). FINO2 can cause suppression of GPX4 activation indirectly, which leads to the execution of ferroptosis (Gaschler et al., 2018). Besides, the direct initiatory agents Ras-selective lethal small molecule 3 (1S,3R-RSL3), ML162 (DPI7), and ML210 (DPI10) are able to inactivate GPX4 bioactivity and enhance resistance to lipid peroxidation during carcinogenesis (Yang et al., 2014).

To date, apart from erastin and RSL3 as ferroptosis-inducing agents (FIN), several conventional chemotherapeutic drugs (Gout et al., 2001) have shown enhanced therapeutic effects related to ferroptosis. The canonical antimalarial drug artemisinin and its derivatives have been demonstrated as having great value in anticancer therapy (Augustin et al., 2020). Chen G. Q. et al. (2020) reported that artemisinin can trigger ferroptosis by increasing cellular free iron Dihydroartemisinin (DHA), a classical artemisinin derivative, has also been shown to have initiatory effect on ferroptosis in both leukemia cells and head and neck squamous carcinoma cells (HNSCC), as reported by recent studies (Lin et al., 2016; Du et al., 2019). Another derivative artesunate also holds the ability to induce ferroptosis in HNSCC cells, and inhibition of Nrf2-ARE pathway can reverse the resistance of HNSCC to artesunate-induced ferroptosis (Roh et al., 2017). In addition, a previous study on sorafenib revealed that it appeared to trigger ferroptosis in a certain concentration (Dixon et al., 2014). Currently, Li et al. (2021) have reported that artesunate synergizing with sorafenib can trigger ferroptosis in hepatocellular carcinoma. Collectively, these findings suggest that some natural products can serve as ferroptosis inducers and reveal novel strategies for anticancer therapies and further figure out the formation of multidrug resistance (MDR).

Notably, there are several tumor-related genes that play a role in manipulating ferroptosis cell death. Certain mutational forms of the tumor suppressor gene TP53 has been recognized as having multiple functions in tumor suppression recently, particularly with regards to regulation of ferroptotic metabolism. After acetylating three lysines $(K 117 R, K 161 R$, and $K 162 R)$, the mutant gene $T P 53^{3 \mathrm{KR}}$ is able to induce ferroptosis and suppress tumor growth by inhibiting SLC7A11 and activating ALOX12 expression (Chu et al., 2019). In addition, TP53 modulates cystine uptake by directly inhibiting SLC7A11 using transcriptional Nrf2 proteins, and inhibits Fe (II) accumulation by inactivating the Nrf2-targeted genes HO-1 and FTH11 (Shin et al., 2018). Mutations within another conventional oncogene Ras can cause activation of Ras proteins and ultimately execute cancer progression. Studies on Ras-mitogenactivated protein kinase (MEK) suggests that upregulation of this oncogenic pathway is able to enhance the sensitivity of cancer cells to ferroptosis by exacerbating lipid peroxidation and generating excess ROS (Ma et al., 2016; Guo et al., 2018). Recent evidence has suggested that KRas is a negative regulator for TP53, which further promotes Nrf2 expression to halt ferroptosis for tumor growth (Yang et al., 2020). In conclusion, ferroptosis has been linked to carcinogenesis, and has significant value in neoplastic diseases. Application of specific small molecules that can target oncogenes and modulate transcriptional factors of ferroptosis need to be considered and further investigated.

\section{NON-CODING RNAS, A PROSPECTIVE POINT OF ONCOGENE ENCODING}

Non-coding RNAs (ncRNAs) refer to RNAs that are transcribed that do not encoding proteins. Since small temporal RNAs were initially discovered in Caenorhabditis elegans as lineage defective 4 (lin-4) and in mammals as lethal 7 (let-7), ncRNAs have been shown to participate in regulating gene expression (Johnsson et al., 2014). The ncRNAs form a physiological control mechanism in mammalian regulatory networks, and participate in another canonical network motif during cancer development (Anastasiadou et al., 2018).

Among ncRNAs, microRNAs (miRNAs) are the most intensively studied ncRNAs in the modulation of carcinogenesis. MiRNAs are endogenous small RNAs, between 21 and 24 nucleotides long, and can be transferred from cell-to-cell by several ways (e.g., exosomes) to alter genetic or epigenetic phenotypes of cancer (Seyed et al., 2020; Maryam et al., 2021). MiRNAs function by base-pairing with complementary sequences within mRNA molecules, leading to inhibition of gene expression at the transcriptional level on the basis of miRNA-mRNA base pairing (Rupaimoole and Slack, 2017). In cancer cells (e.g., gynecologic cancer), some miRNAs function as oncogenes, while others function as tumor suppressors (Zahra et al., 2021). Numerous studies have demonstrated that miRNAs act as oncogenes in cancer development (Neda et al., 2021). Importantly, previous reports have revealed that miRNAs may influence the effect of ferroptosis inducers. Exosomal miR-4443 has been reported to inhibit cisplatin-induced ferroptosis and promote cisplatin resistance in NSCLC (Song et al., 2021). In lung adenocarcinoma cell A549, Deng et al. (2021) found that miR-324-3p can enhance cisplatin-induced ferroptosis by targeting GPX4 directly. Moreover, Ma et al. (2021) reported that miR-424-5p knockdown sensitized ovarian cancer cells to erastin and RSL3 and executed ferroptosis by targeting ACSL4. These findings suggest that miRNAs may have a key regulatory function in MDR, thereby holding great promise for the development of novel and effective therapies for cancer treatment.

With the explanation of miRNA efficacy in cancer treatment, more attention has been paid to ncRNAs in order to investigate whether other ncRNAs, such as circRNAs, have similar bioactivity as miRNAs in order to modulate the carcinogenic processes. Moreover, several reports have assessed the potential effectiveness of circRNAs to repress the miRNA-mediated mRNA editing via absorbing tumorigenic regulators as miRNA-sponges (Hansen et al., 2013; Memczak et al., 2013; Li et al., 2015; Wang et al., 2016; Zheng et al., 2016; Peng et al., 2017). Notably, with a specific circular structure stabilized by covalent bonding, circRNAs suggest a steady regulatory potency of oncogenesis in cytoplasm of cancer cells.

Taken together, based on current biofunctions of ncRNAs in cancer growth, this review has focused on exerting these molecular regulators in ferroptosis and pay greater attention 
to the promising efficacy of circRNAs, which has not been reported until now.

\section{ROLE OF NCRNAS IN FERROPTOSIS AND ITS MOLECULAR PATHWAYS}

Recently, ncRNAs have become increasingly recognized as playing a significant role in mediating the development of cancer (Slack and Chinnaiyan, 2019). LncRNAs and miRNAs are the two most widely studied ncRNAs. MiRNAs and lncRNAs, both of which can act alone or interact with each other, take part in regulating the inter-related steps and genetic mediators of programmed cell death, including ferroptosis.

Notably, miRNAs are significantly involved in regulating ferroptosis among cancer cells (Bridges et al., 2012). In melanoma cells, miR-9 is able to inhibit catalytic efficacy of glutamic-oxaloacetic transaminase 1 (GOT1) and halt transamination of a-ketoglutarate (a-KG), while inhibition of miR-9 causes accumulation of lipid ROS, and eventually exacerbates the enforcement of ferroptosis (Zhang et al., 2018). In addition, upregulation of miR-137 causes inhibition of glutamine transporter SLC1A5, and protects cellular proliferation and colonization against ferroptosis in melanoma (Luo et al., 2018). MiR-7-5p, which has an effect on cell migration and invasion in melanoma (Giles et al., 2013), is associated with radio-resistance of cancer cells by decreasing expression of ferrous iron within the cytoplasm (Tomita et al., 2019). Studies in melanoma also suggest specific targets of ferroptosis in order to further identify modulatory efficacy of miRNAs.

GSH homeostasis is known to be a key factor of oncogenesis. Recent studies have highlighted the function of specific miRNAs in modulating intracellular GSH levels. For example, miR-4715$3 p$ is inhibited by overexpression of AURKA (aurora kinase A), a serine threonine kinase that has a significant role in mitotic progression in both normal cells and cancers (Li et al., 2018). Reconstitution of miR-4715-3p has been validated to be an essential method that hinders the process of tumorigenesis by inhibiting GPX4 and enhancing cisplatin sensitivity (Gomaa et al., 2019). Other miRNAs, including miR-185, can prevent human colon adenocarcinoma cells from sustaining oxidative damage by upregulating glutathione peroxidase 2 (GPX2) (Maciel-Dominguez et al., 2013). In gastric cancer, miR-103a$3 p$ directly represses GLS2 expression, which helps maintain cellular Gln levels and prevents execution of ferroptosis (Niu et al., 2019). Moreover, several other miRNAs, including miR-155 (Chen et al., 2017), miR-144-3p (Sun et al., 2017), miR-28 (Yang et al., 2011), miR-181-c (Jung et al., 2017), miR-93 (Singh et al., 2013), and miR-142 (Wang N. et al., 2017), have been identified to downregulate Nrf2 and promote ferroptosis in cancer cells. Taken together, several molecular targets of glutathione metabolism can be specific transcriptional targets for miRNAs, which are known to be tightly associated with the ferroptosis and oncogenesis.

As mentioned previously, SLC7A11 is an important factor that protects cells against ferroptosis due to the antioxidative efficacy enhanced by cystine uptake for cellular GSH metabolism. In oral squamous cell carcinoma (OSCC), miR-375 acts as a tumor suppressor by inhibiting SLC7A11 expression, leading to ferroptosis (Wu et al., 2017). Similar regulatory pathways have been identified for miR-26b in breast cancer (Liu et al., 2011). Thus, it is clear that certain miRNAs execute ferroptosis in cancer cells by inhibiting SLC7A11 expression (Table 1).

Recently, scientists have paid significant attention to the relationship between miRNAs and lincRNAs in the regulation of transcription of ferroptosis and oncogenesis. LINC00336, a type of lincRNA with large intergenic transcripts that cover over $200 \mathrm{nt}$, has been reported to enhance proliferation of lung cancer cells and inhibit ferroptosis through an ELAVL1-dependent manner (Wang M. et al., 2019). Consistent with CBS, miR-6852 can aggravate ferroptosis and restrict tumorigenesis by negatively regulating the bioactivity of CBS, which mediates ferroptosis inhibition. This modulation is protected by overexpression of $\mathrm{LSH}$, which can attenuate $\mathrm{p} 53$ recruitment to the promoter region of ELAVL1. Studies have revealed a role for LINC00336 as a competing endogenous RNA (ceRNA) to inactivate miR-6852 in lung cancer, thus allowing it to be potential target of lung cancer therapy. To date, limited studies have evaluated the interaction between lincRNAs and ferroptosis. However, studies have shown that, similar to miRNAs, lincRNAs can act as dual regulators for ferroptosis, either by absorbing certain miRNAs to alter their effects or combining with certain enzymes to have an effect on the bioactivity of cancer cells (Figure 2).

Collectively, miRNAs have important regulatory functions, either as tumor suppressors or oncogene inducers, by downregulating transcription of essential genes that are associated with tumorigenesis or ferroptosis or degrading exon generations at the mRNA level. It is plausible that these miRNAs can promote ferroptosis by inactivating certain genes. Therefore, there is an urgent need to explore the relevant molecular mechanisms that underlie miRNAs, as well as to identify the role of miRNAs in the mechanisms of classical anticancer drugs, such as cisplatin and sorafenib.

\section{CIRCRNA AND FERROPTOSIS}

Advanced research approaches on lincRNAs have provided guidance for perspective studies on other lncRNAs, such as circRNAs, which are RNAs that are formed with covalently closed continuous loops. There are three categories of circRNAs, including exonic circRNA (ecircRNA), which are cyclized from exon, circular intronic RNA (ciRNA) from introns and exonicintronic circRNA (EIcircRNA) (Miri et al., 2012; Memczak et al., 2013). CircRNAs have diverse gene-regulatory functions, and can act as miRNA sponges, protein translators (Legnini et al., 2017), and protein scaffolds. To date, studies have revealed unique characteristics of circRNAs, including abundance, conservation and tissue-specificity, all of which may serve as biomarkers of certain pathological processes, compared to miRNAs (Guo et al., 2014; Wang et al., 2014; Xia et al., 2017).

Previous studies have assessed the functional roles of circRNAs in several physiological and pathological conditions, particularly in the development and diagnosis of cancer (Table 2). Increasing evidence shows that circRNAs mediate autophagy, apoptosis 
TABLE 1 | Biofunction of miRNAs in regulating ferroptosis in cancer cells.

\begin{tabular}{|c|c|c|c|c|c|c|c|c|}
\hline miRNA & $\begin{array}{l}\text { Target } \\
\text { gene }\end{array}$ & $\begin{array}{l}\text { Expression } \\
\text { changes }\end{array}$ & Biofunction & Cancer types & $\begin{array}{l}\text { Ferroptosis } \\
\text { progression }\end{array}$ & Model & Cell lines & References \\
\hline miR-9 & GOT1 & Downregulation & $\begin{array}{l}\text { Inhibit lipid peroxidation } \\
\text { and iron accumulation }\end{array}$ & Melanoma & Suppression & $\begin{array}{l}\text { Cell } \\
\text { culture }\end{array}$ & A375, G-361 & $\begin{array}{l}\text { Zhang et al., } \\
2018\end{array}$ \\
\hline $\begin{array}{l}\text { miR-9- } \\
5 p\end{array}$ & GOT1 & Downregulation & $\begin{array}{l}\text { Inhibit glutamine } \\
\text { metabolism and redox } \\
\text { homeostasis }\end{array}$ & $\begin{array}{l}\text { Pancreatic } \\
\text { cancer }\end{array}$ & Suppression & $\begin{array}{l}\text { Cell } \\
\text { culture }\end{array}$ & $\begin{array}{l}\text { H6c7, BxPC3, } \\
\text { Panc1, } \\
\text { Miapaca2, } \\
\text { AsPC1, } \\
\text { CFPAC1 }\end{array}$ & $\begin{array}{l}\text { Wang J. } \\
\text { et al., } 2019\end{array}$ \\
\hline $\begin{array}{l}\mathrm{miR}- \\
133 \mathrm{~b}\end{array}$ & GST- $\pi$ & Downregulation & $\begin{array}{l}\text { Modulate intracellular } \\
\text { glutathione metabolism }\end{array}$ & Ovarian cancer & Promotion & $\begin{array}{l}\text { Cell } \\
\text { culture }\end{array}$ & $\begin{array}{l}\text { A2780, } \\
\text { A2780/Taxol, } \\
\text { A2780/DDP, } \\
\text { OVCAR3 }\end{array}$ & $\begin{array}{l}\text { Chen et al., } \\
2015\end{array}$ \\
\hline $\begin{array}{l}\text { miR- } \\
103 a- \\
3 p\end{array}$ & GLS2 & Downregulation & $\begin{array}{l}\text { Inhibit transportation of } \\
\text { glutamate Modulate } \\
\text { glutamine metabolism }\end{array}$ & Gastric cancer & Suppression & $\begin{array}{l}\text { Cell } \\
\text { culture }\end{array}$ & $\begin{array}{l}\text { MGC-803, } \\
\text { MKN-415 }\end{array}$ & $\begin{array}{l}\text { Niu et al., } \\
2019\end{array}$ \\
\hline $\begin{array}{l}\mathrm{miR}- \\
122\end{array}$ & $\begin{array}{l}\text { GLS2 } \\
\text { SLC1A5 }\end{array}$ & Downregulation & $\begin{array}{l}\text { Modulate glutamine } \\
\text { metabolism }\end{array}$ & $\mathrm{HCC}$ & Promotion & $\begin{array}{l}\text { Mice } \\
\text { model }\end{array}$ & EC4 & $\begin{array}{l}\text { Sengupta } \\
\text { et al., } 2020\end{array}$ \\
\hline $\begin{array}{l}\text { miR- } \\
137\end{array}$ & SLC1A5 & Downregulation & $\begin{array}{l}\text { Decrease glutamine } \\
\text { uptake and MDA } \\
\text { accumulation; Increase } \\
\text { sensitivity ferroptosis }\end{array}$ & Melanoma & Suppression & $\begin{array}{l}\text { Cell } \\
\text { culture }\end{array}$ & A375, G-361 & $\begin{array}{l}\text { Luo et al., } \\
2018\end{array}$ \\
\hline $\begin{array}{l}\text { miR- } \\
375\end{array}$ & SLC7A11 & Downregulation & $\begin{array}{l}\text { Modulate cystine } \\
\text { metabolism }\end{array}$ & oscc & Promotion & $\begin{array}{l}\text { Cell } \\
\text { culture }\end{array}$ & $\begin{array}{l}\text { Hs680, Fadu, } \\
\text { SCC-25, } \\
\text { CAL-27, } \\
\text { Tca8113 }\end{array}$ & $\begin{array}{l}\text { Wu et al., } \\
2017\end{array}$ \\
\hline $\begin{array}{l}\mathrm{miR}- \\
27 \mathrm{a}\end{array}$ & SLC7A11 & Downregulation & $\begin{array}{l}\text { Mediate regulation of } \\
\text { intracellular glutathione }\end{array}$ & Bladder cancer & Promotion & $\begin{array}{l}\text { Cell } \\
\text { culture }\end{array}$ & $\mathrm{Ej} / \mathrm{T} 24, \mathrm{RT} 112$ & $\begin{array}{l}\text { Drayton } \\
\text { et al., } 2014\end{array}$ \\
\hline $\begin{array}{l}\mathrm{miR}- \\
4715- \\
3 p\end{array}$ & AURKA & Downregulation & $\begin{array}{l}\text { Inhibit GPX4 bioactivity } \\
\text { Enhance cisplatin } \\
\text { sensitivity }\end{array}$ & $\begin{array}{l}\text { Gastrointestinal } \\
\text { cancer }\end{array}$ & Promotion & $\begin{array}{l}\text { Cell } \\
\text { culture }\end{array}$ & $\begin{array}{l}\text { OE33, } \\
\text { MKN45, } \\
\text { STKM2 }\end{array}$ & $\begin{array}{l}\text { Gomaa } \\
\text { et al., } 2019\end{array}$ \\
\hline $\begin{array}{l}\text { miR- } \\
522\end{array}$ & ALOX15 & Upregulation & $\begin{array}{l}\text { Inhibit lipid-ROS } \\
\text { accumulation }\end{array}$ & Gastric cancer & Suppression & $\begin{array}{l}\text { Male } \\
\text { nude } \\
\text { mice }\end{array}$ & $\begin{array}{l}\text { SGG-7901, } \\
\text { MGC-803 } \\
\text { MKN-45 }\end{array}$ & $\begin{array}{l}\text { Zhang } \mathrm{H} \text {. } \\
\text { et al., } 2020\end{array}$ \\
\hline $\begin{array}{l}\text { miR- } \\
214-3 p\end{array}$ & ATF4 & Downregulation & $\begin{array}{l}\text { Enhance } \\
\text { erastin-induced lipid } \\
\text { peroxidation }\end{array}$ & Hepatoma & Promotion & $\begin{array}{l}\text { Nude } \\
\text { mice }\end{array}$ & $\begin{array}{l}\text { HepG2, } \\
\text { Нер3B }\end{array}$ & $\begin{array}{l}\text { Bai et al., } \\
2020\end{array}$ \\
\hline $\begin{array}{l}\mathrm{miR}- \\
17-92\end{array}$ & $\begin{array}{l}\text { A2O/ } \\
\text { ACSL4 }\end{array}$ & Downregulation & Inhibit lipid peroxidation & Endothelial cells & Suppression & $\begin{array}{l}\text { Cell } \\
\text { culture }\end{array}$ & HUVEC & $\begin{array}{l}\text { Xiao et al., } \\
2019\end{array}$ \\
\hline $\begin{array}{l}\text { miR- } \\
205\end{array}$ & ACSL4 & Downregulation & $\begin{array}{l}\text { Modulate abnormal } \\
\text { lipid metabolism }\end{array}$ & $\mathrm{HCC}$ & Promotion & $\begin{array}{l}\text { Cell } \\
\text { culture }\end{array}$ & HepG2 & $\begin{array}{l}\text { Cui et al., } \\
2014\end{array}$ \\
\hline $\begin{array}{l}\mathrm{miR}- \\
144\end{array}$ & Nrf2 & Downregulation & $\begin{array}{l}\text { Suppress Nrf2/HO-1 } \\
\text { pathway Reverse } \\
\text { chemoresistance to } \\
\text { 5-FU }\end{array}$ & $\mathrm{HCC}$ & Promotion & $\begin{array}{l}\text { Cell } \\
\text { culture }\end{array}$ & $\begin{array}{l}\text { Bel-7402, } \\
\text { Bel-7402/5-FU }\end{array}$ & $\begin{array}{l}\text { Zhou et al., } \\
2016\end{array}$ \\
\hline miR-28 & Nrf2 & Downregulation & $\begin{array}{l}\text { Mediate Nrf2 protein } \\
\text { degradation in } \\
\text { Keap1-independent } \\
\text { manner }\end{array}$ & Breast cancer & Promotion & $\begin{array}{l}\text { Cell } \\
\text { culture }\end{array}$ & $\begin{array}{l}\text { MCF-7, } \\
\text { HEK293T }\end{array}$ & $\begin{array}{l}\text { Yang et al., } \\
2011\end{array}$ \\
\hline $\begin{array}{l}\mathrm{miR}- \\
432\end{array}$ & Keap1 & Downregulation & $\begin{array}{l}\text { Upregulate NRF2 } \\
\text { protein Enhance NRF2 } \\
\text { stabilization }\end{array}$ & ESCC & Suppression & $\begin{array}{l}\text { Cell } \\
\text { culture }\end{array}$ & $\begin{array}{l}\text { HeLa, } \\
\text { SH-SY5Y }\end{array}$ & $\begin{array}{l}\text { Akdemir } \\
\text { et al., } 2017\end{array}$ \\
\hline $\begin{array}{l}\text { miR- } \\
148 b\end{array}$ & $\begin{array}{l}\text { ERMP1/ } \\
\text { Nrf2/HIF- } \\
1\end{array}$ & Downregulation & $\begin{array}{l}\text { Increase intracellular } \\
\text { ROS level }\end{array}$ & $\begin{array}{l}\text { Endometrial } \\
\text { cancer }\end{array}$ & Promotion & $\begin{array}{l}\text { Cell } \\
\text { culture }\end{array}$ & RL95-2 & $\begin{array}{l}\text { Qu et al., } \\
2018\end{array}$ \\
\hline $\begin{array}{l}\mathrm{miR}- \\
507\end{array}$ & Nrf2/ME1 & Downregulation & $\begin{array}{l}\text { Inhibit Nrf2-mediated } \\
\text { oncogenic pathway }\end{array}$ & ESCC & Promotion & $\begin{array}{l}\text { Cell } \\
\text { culture }\end{array}$ & $\begin{array}{l}\text { HeLa, LK-2, } \\
\text { A549, JHH-5 }\end{array}$ & $\begin{array}{l}\text { Yamamoto } \\
\text { et al., } 2014\end{array}$ \\
\hline $\begin{array}{l}\mathrm{miR}- \\
155\end{array}$ & Nrf2 & Upregulation & $\begin{array}{l}\text { Decrease intracellular } \\
\text { ROS level }\end{array}$ & Lung cancer & Suppression & $\begin{array}{l}\text { Cell } \\
\text { culture }\end{array}$ & A549 & $\begin{array}{l}\text { Gu et al., } \\
2017\end{array}$ \\
\hline
\end{tabular}




\begin{tabular}{|c|c|c|c|c|c|c|c|c|}
\hline miRNA & $\begin{array}{l}\text { Target } \\
\text { gene }\end{array}$ & $\begin{array}{l}\text { Expression } \\
\text { changes }\end{array}$ & Biofunction & Cancer types & $\begin{array}{l}\text { Ferroptosis } \\
\text { progression }\end{array}$ & Model & Cell lines & References \\
\hline $\begin{array}{l}\text { miR- } \\
340\end{array}$ & Nrf2 & Downregulation & $\begin{array}{l}\text { Inhibit } \\
\text { Nrf2/NQO-1/HO-1 } \\
\text { expression }\end{array}$ & $\mathrm{HCC}$ & Promotion & $\begin{array}{l}\text { Cell } \\
\text { culture }\end{array}$ & $\begin{array}{l}\text { HepG2, } \\
\text { HepG2/CDDP }\end{array}$ & $\begin{array}{l}\text { Shi et al., } \\
2014\end{array}$ \\
\hline $\begin{array}{l}\mathrm{miR}- \\
365\end{array}$ & Nrf2 & Downregulation & $\begin{array}{l}\text { Decrease Nrf2 } \\
\text { expression; Increase } \\
\text { intracellular ROS } \\
\text { generation }\end{array}$ & $\mathrm{HCC}$ & Promotion & $\begin{array}{l}\text { Cell } \\
\text { culture }\end{array}$ & HepG2 & $\begin{array}{l}\text { Gao et al., } \\
2018\end{array}$ \\
\hline $\begin{array}{l}\text { miR- } \\
378\end{array}$ & $\mathrm{Nrf2}$ & Upregulation & $\begin{array}{l}\text { Decrease intracellular } \\
\text { ROS generation }\end{array}$ & NSCLC & Suppression & $\begin{array}{l}\text { Cell } \\
\text { culture } \\
\text { Animal } \\
\text { model }\end{array}$ & $\begin{array}{l}\mathrm{NCl}-\mathrm{H} 292, \\
\mathrm{NCl}-\mathrm{H} 460 \\
\text { A549, } \\
\text { SK-MES-1 }\end{array}$ & $\begin{array}{l}\text { Skrzypek } \\
\text { et al., } 2013\end{array}$ \\
\hline $\begin{array}{l}\mathrm{miR}- \\
125 b\end{array}$ & $\begin{array}{l}\text { PRXL2A } \\
\text { Nrf2 }\end{array}$ & Downregulation & $\begin{array}{l}\text { Increase intracellular } \\
\text { ROS level Suppress } \\
\text { Nrf2 expression }\end{array}$ & oscc & Promotion & $\begin{array}{l}\text { Cell } \\
\text { culture }\end{array}$ & $\begin{array}{l}\text { SAS, OECM1, } \\
\text { HSC3, FaDu, } \\
\text { OC3, 293T, } \\
\text { NOK }\end{array}$ & $\begin{array}{l}\text { Chen et al., } \\
2019\end{array}$ \\
\hline $\begin{array}{l}\mathrm{miR}- \\
29 b-1- \\
5 p\end{array}$ & AKT/Nrf2 & Downregulation & $\begin{array}{l}\text { Increase intracellular } \\
\text { ROS level }\end{array}$ & Breast cancer & Promotion & $\begin{array}{l}\text { Cell } \\
\text { culture }\end{array}$ & MDA-MB-231 & $\begin{array}{l}\text { De Blasio } \\
\text { et al., } 2020\end{array}$ \\
\hline $\begin{array}{l}\mathrm{miR}- \\
141\end{array}$ & Keap1 & Downregulation & $\begin{array}{l}\text { Modulate Keap1 } \\
\text { expression Active } \\
\text { Nrf2/IKK } \beta \text { pathway }\end{array}$ & Ovarian cancer & Suppression & $\begin{array}{l}\text { Cell } \\
\text { culture }\end{array}$ & $\begin{array}{l}\text { A2780, } \\
\text { A2780/DDP }\end{array}$ & $\begin{array}{l}\text { van } \\
\text { Jaarsveld } \\
\text { et al., } 2013\end{array}$ \\
\hline $\begin{array}{l}\text { miR- } \\
200 a\end{array}$ & Keap1 & Downregulation & $\begin{array}{l}\text { Active Keap1/Nrf2 } \\
\text { pathway }\end{array}$ & ESCC & Suppression & $\begin{array}{l}\text { Cell } \\
\text { culture }\end{array}$ & $\begin{array}{l}\text { KYSE150, } \\
\text { KYSE180, } \\
\text { KYSE410, } \\
\text { KYSE510 }\end{array}$ & $\begin{array}{l}\text { Liu et al., } \\
2015\end{array}$ \\
\hline
\end{tabular}

and cell proliferation (Bahn et al., 2015; Du et al., 2017; Gao et al., 2017; Zeng et al., 2017). Most circRNAs are characterized by the high stability and specificity (Salzman et al., 2013). There are several detecting methods (e.g., RTqPCR, in situ hybridization, high-throughput sequencing) that are mature enough for circRNA profiles. CircRNAs are reported to abnormally express in many cancers, such as hepatocellular carcinoma (Aishanjiang et al., 2021), renal cell carcinoma (Frey et al., 2021), glioblastoma (Wei et al., 2021), and gastric cancer (Jiang et al., 2021). Recent studies show that circRNAs are able to reverse resistance to conventional therapeutic strategies in several cancers, such as circLIFR (Zhang et al., 2021b), ciRS122 (Wang et al., 2020), and Cdrlas (Yuan et al., 2019) in chemoresistance and circATRNL1 (Chen G. et al., 2020) in radioresistance. Taken together, circRNAs are reliable biomarkers in diagnosis, prognosis, and potential targets in clinical therapies.

Currently, only limited reports on the function of circRNAs in ferroptosis have been explored so far (Li et al., 2020; Liu Z. et al., 2020; Xu et al., 2020; Zhang H. Y. et al., 2020; Wang et al., 2021; Wu et al., 2021; Zhang et al., 2021a; Table 3). Most of these studies have focused on the sponging effect of circRNAs, while Liu Z. et al. have brought insights into the role of circRNA $C I A R S$ as a protein scaffold in mediating RNA binding protein AlkB Homolog 5 (ALKBH5) (Liu Z. et al., 2020). Moreover, they have established a sorafenib-treated HCC model to further explore the mechanism underlying ferroptosis and autophagy. By reviewing these papers, we highlight the multiple mechanisms of circRNAs in regulating ferroptosis (e.g., miRNA sponges, protein scaffolds) (Figure 3). As circRNAs have been reported to regulate the transcription and be translated into proteins (Verduci et al., 2020), we assume that it is of high value for further research to detect the similar mechanisms of circRNAs in regulating ferroptosis and carcinogenesis. Besides, future investigations can establish experimental models as Liu Z. et al. (2020) did to explain the participation of circRNAs and ferroptosis in chemotherapeutic drugs against tumors, which may serve as guidance for potential applications in clinic.

CircRNAs provide a promising value in the treatment of MDR of cancers, particularly when targeting the relationship between circRNAs and ferroptosis. Accordingly, ferroptosis has paved the way to develop gene-oriented strategies and more precisive gene therapies than conventional anticancer drugs. Shin et al. (2018) have discovered that activation of the Nrf2-ARE pathway contributes to the resistance of HNC cells to GPX4 inhibition, and inhibition of this pathway reverses resistance to ferroptosis among HNC cells. MT-1G has been demonstrated as a novel regulator of ferroptosis in HCC cells. The molecular mechanism of MT-1G's role in sorafenib resistance involves inhibiting ferroptosis. Inhibition of MT-1G by RNA interference increases glutathione depletion and lipid peroxidation (Sun et al., 2016), which demonstrates that CAFs secrete exosomal miR-522 in order to inhibit ferroptosis in cancer cells by targeting ALOX15 and blocking lipid-ROS accumulation, resulting in decreased chemo-sensitivity of cisplatin (Zhang H. et al., 2020). However, further investigation into the role of circRNAs in cancer diagnosis and prognostic estimates needs to be addressed.

Based on previous evidence, we can assume that certain circRNAs likely act as miRNA sponges in order to inhibit 


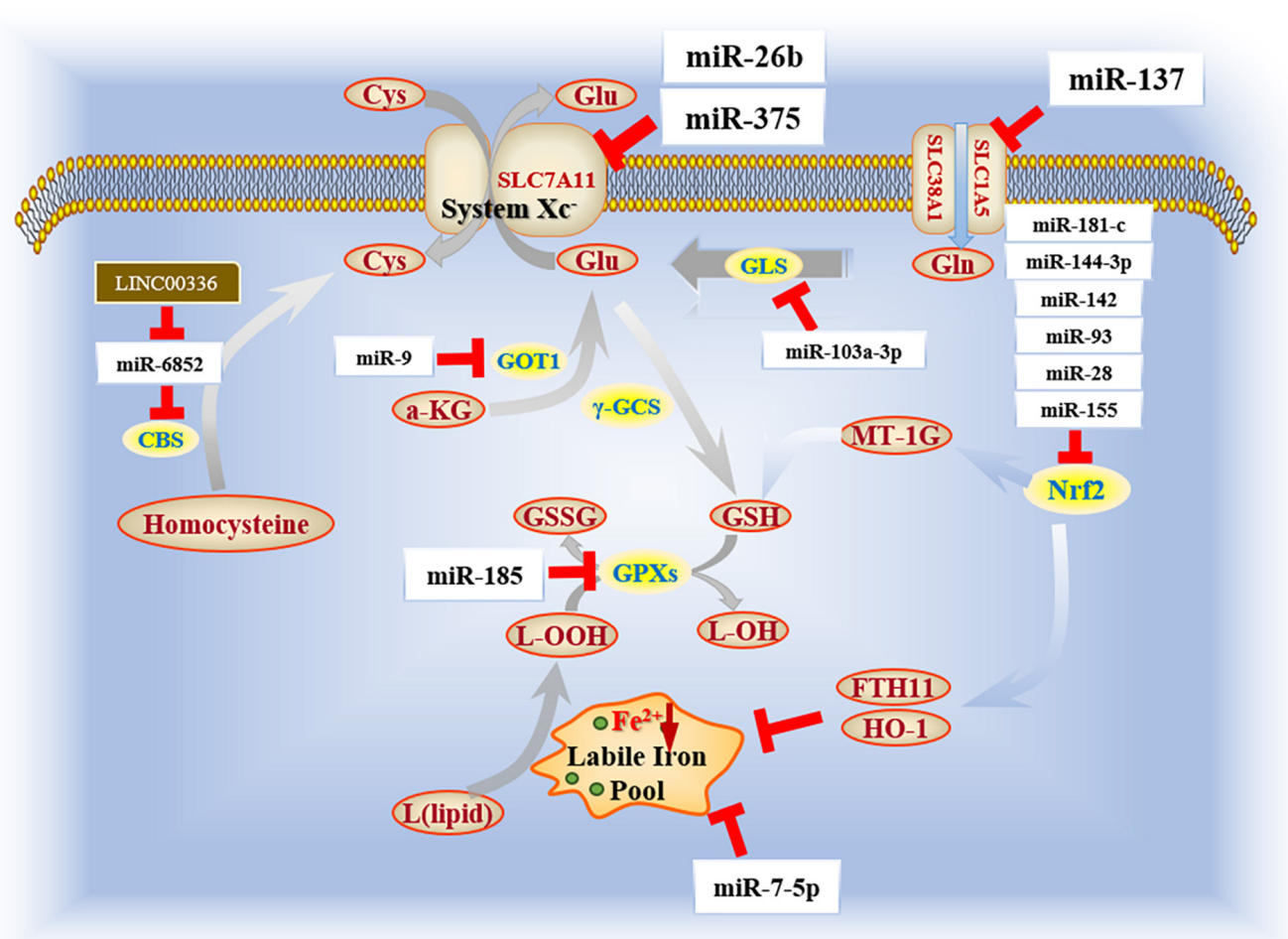

FIGURE 2 | Biofunction of miRNAs in ferroptosis mechanism. Current reports focus on several essential enzymes (e.g., Nrf2, GLS, and GPXs) that impact ferroptosis progression. Among those, Nrf2 holds an irreplaceable role in the regulatory network because of its double value in both ferroptosis and apoptosis.

TABLE 2 | Our previous studies related to circRNAs in osteogenesis and carcinogenesis.

\begin{tabular}{|c|c|c|c|c|}
\hline circRNA & Expression & Target & Biofunction & References \\
\hline circCDR1as & Up & $\mathrm{AKT} / \mathrm{ERK}_{1 / 2} / \mathrm{mTOR}$ & $\begin{array}{l}\text { Promoting autophagy in OSCC cells via sponging miR-671-5p } \\
\text { Enhancing OSCC cells viability under a hypoxia microenvironment }\end{array}$ & Gao et al., 2019a \\
\hline circPKD2 & Down & miR-204-3p/APC2 & $\begin{array}{l}\text { Upregulating APC2 expression via sponging miR-204-3p Inhibiting } \\
\text { OSCC carcinogenesis }\end{array}$ & Gao et al., 2019b \\
\hline hsa_circ_0072387 & Down & $\begin{array}{l}\mathrm{miR}-29-3 p / \mathrm{miR}-141- \\
\text { 3p-MMP2/BCL2/PTEN }\end{array}$ & A potential biomarker in OSCC diagnosis & Dou et al., 2020b \\
\hline circFLNA & Up & Fucoidan/circFLNA & Inhibiting OSCC progression & Zhang N. et al., 2020 \\
\hline mmu_circ_0001066 & Up & miR-16 & $\begin{array}{l}\text { Restoring the BP-mediated suppression of osteoclasto-genesis via } \\
\text { sponging miR-16 }\end{array}$ & Zhang et al., 2021c \\
\hline circCDK8 & Up & mTOR & $\begin{array}{l}\text { Repressing the osteogenic differentiation of PDLSC by triggering } \\
\text { autophagy activation in a hypoxic microenvironment }\end{array}$ & Zheng et al., 2021 \\
\hline ciRS-7 & Up & $\mathrm{miR}-7 / \mathrm{RAF}-1 / \mathrm{PIK} 3 \mathrm{CD}$ & Enhancing metastatic progress-ion of OSCC via sponging miR-7 & Dou et al., 2020a \\
\hline
\end{tabular}

modulation of downstream transcription in cancer cells, and guide the probable direction of elucidating the underlying features of circRNAs in classical ferroptosis or tumorigenic mechanisms. Furthermore, circRNAs can exert advantages of molecular construction, which directly affects upstream transcriptions. CircRNAs are able to be translated into proteins, which suggests that applications of their expression as regulators can disturb upstream genes. Nevertheless, many controversial views have emerged in circRNAs research and application. As only a limited number of circRNAs have been reported as miRNA sponges, while others only have few miRNA binding sites (Wang et al., 2014), are there other methods that circRNAs take in regulating target mRNAs? Moreover, how can circRNAs proteintranslating effect be distinguished from others? Additionally, it is unclear whether circRNAs are degraded or inhibited at the end due to its unique structure. Taking into consideration, circRNAs, which are a controversial type of ncRNAs, likely have distinctive mechanisms in interacting with other ncRNAs and modulating certain cellular processes, such as ferroptosis.

In brief, there is a considerable value of bioactivity among circRNAs which can contribute to further studies in ferroptosis progression and oncogenic regulation, despite the fact that the relationship between ferroptosis and circRNAs requires more identification. 
TABLE 3 | Current reports related to circRNAs in modulating miRNA-regulated ferroptosis progression.

\begin{tabular}{|c|c|c|c|c|c|c|}
\hline circRNA & Target & Biofunction & $\begin{array}{l}\text { Cancer } \\
\text { types }\end{array}$ & $\begin{array}{l}\text { Ferroptosis } \\
\text { progression }\end{array}$ & Cell lines & References \\
\hline circ-0008035 & $\begin{array}{l}\text { miR- } \\
\text { 599/EIF4A1 }\end{array}$ & Inhibiting miR-599 & $\begin{array}{l}\text { Gastric } \\
\text { cancer }\end{array}$ & Up & GE8-1 HGC-27 AGS & Li et al., 2020 \\
\hline circ-TTBK2 & miR-761/ITGB8 & Inhibiting miR-761 & Glioma & Down & LN229 U251 NHA & $\begin{array}{l}\text { Zhang H. Y. et al., } \\
2020\end{array}$ \\
\hline circ-clARS & ALKBH5 (RBP) & Siliencing ALKBH5 & $\mathrm{HCC}$ & Up & HepG2 SMMC-7721 Huh-7 & Liu Z. et al., 2020 \\
\hline circ-IL4R & $\begin{array}{l}\text { miR-541- } \\
3 p / G P X 4\end{array}$ & Sponging miR-541-3p & $\mathrm{HCC}$ & Down & THLE-2 HuH-7 HCCLM3 & Xu et al., 2020 \\
\hline circ-EPSTI1 & $\begin{array}{l}\mathrm{miR}-375 / \mathrm{miR}- \\
\text { 409-3p/miR- } \\
\text { 515-5p- } \\
\text { SLC7A11 }\end{array}$ & $\begin{array}{l}\text { Sponging miRNAs to upregulate } \\
\text { SLC7A11 expression }\end{array}$ & $\begin{array}{l}\text { Cervical } \\
\text { cancer }\end{array}$ & Up & CaSki HeLa HcerEpic & Wu et al., 2021 \\
\hline circ-RHOT1 & $\begin{array}{l}\text { miR-106a- } \\
\text { 5p/STAT3 }\end{array}$ & $\begin{array}{l}\text { Contributing to malignant progression } \\
\text { and attenuating ferroptosis }\end{array}$ & $\begin{array}{l}\text { Breast } \\
\text { cancer }\end{array}$ & Down & MDA-MB-231 T47D & Zhang et al., 2021a \\
\hline circ-0007142 & $\begin{array}{l}\text { miR-847- } \\
\text { 3p/GDPD5 }\end{array}$ & $\begin{array}{l}\text { Upregulating GDPD5 and reversing } \\
\text { miR-847-3p-mediated tumor inhibition }\end{array}$ & CRC & Down & HCT116 SW620 SW480 & Wang et al., 2021 \\
\hline
\end{tabular}

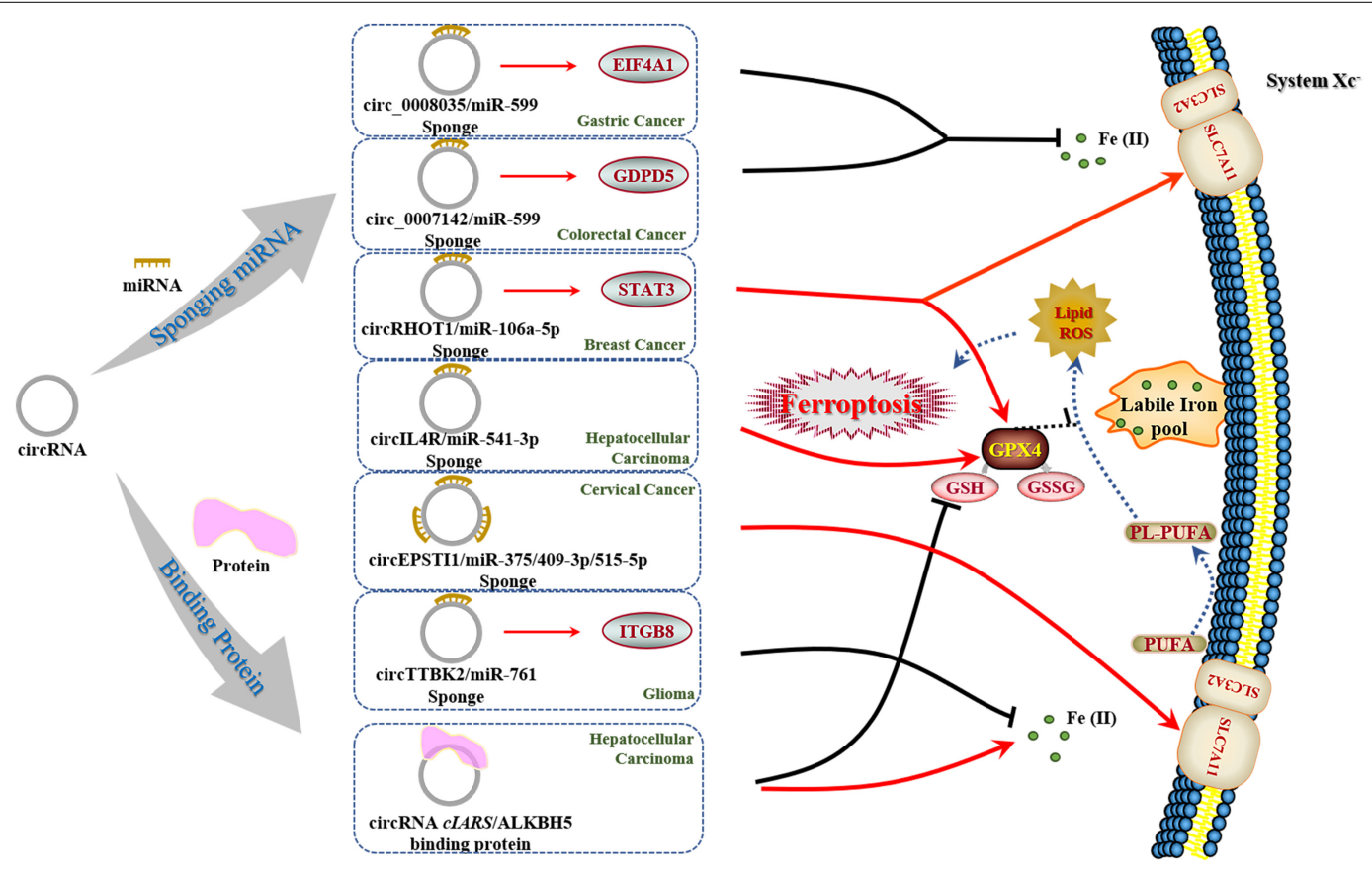

FIGURE 3 | Regulatory effect of circRNAs on ferroptosis in cancers. In the regulation of ferroptosis, circRNAs present two distinct mechanisms based on recent reports. There is only one circRNA (termed cIARS) that is able to execute ferroptosis in cancer cells as reported. Moreover, clARS holds novel promise in interacting with proteins, which needs to be deeply addressed for further work.

\section{DISCUSSION}

In conclusion, ferroptosis not only helps maintain a dynamic equilibrium under physiologic conditions, but also acts as an effective biomechanism to hinder tumorigenic progression in cancer therapies. The efficacy of tumor suppression is executed by dysregulating cystine uptake, glutathione metabolism and redox homeostasis. Mediating ferroptosis may help provide specific molecular targets for suppressing oncogenesis, and can be used in estimating prognosis of neoplastic diseases. As more ferroptosis inducers have been identified, several compounds have emerged as key factors to protect organisms from malignant tumors by exacerbating cell death at the translational level. Moreover, studies of erastin indicate that these ferroptosis inducers likely have multiple targets in regulating ferroptosis mechanisms and influence the expression of ncRNAs, such as miRNAs. Importantly, with the exception of the canonical anticancer drugs, several non-neoplastic drugs have been identified as exerting their capacity to promote the ferroptosis process and transcriptional regulation in cancer cells. Intriguingly, artemisinin and its derivatives have shown enhanced anticancer values synergizing with classical antitumor drugs. These findings 
contribute to identifying viable pharmacological therapies in cancer treatment. Thus, ferroptosis is likely regarded as an effective clinical strategy in order to avoid chemo-resistance in anticancer treatment.

Numerous studies have recognized miRNAs as being able to modulate oncogenes and genes involved in ferroptosis. miRNAs provide potential gene therapy of cancer treatment by intentionally promoting exacerbation of ferroptosis and dysfunction of oncogenic expression at the transcriptional level. It has been reported that the interaction between miRNAs and anticancer drugs has diverse effects on oncogenesis. Some miRNAs (e.g., miR-522, miR-4443) are able to enhance resistance to cisplatin by inhibiting ferroptosis (Zhang $\mathrm{H}$. et al., 2020; Song et al., 2021), while others (e.g., miR4715-3p, miR-324-3p) sensitize cancer cells to cisplatin via induction of ferroptosis (Gomaa et al., 2019; Deng et al., 2021). In addition, the bioactivity of circRNAs has been implicated in the progression of ferroptosis and oncogenic regulation. With a unique structure, circRNAs are more stable and specific in expression compared to miRNAs. It has been widely reported that circRNAs prevalently exist in cancers and serve as diagnostic biomarkers of diverse tumors (Wang Y. et al., 2017; Zhong et al., 2018). CircRNAs are able to not only disrupt regulation of miRNAs in circRNAmiRNA-mRNA regulatory networks, but also interacting with transcripts, proteins and even translating proteins to target oncogenes. CircRNAs have a promising future in an underlying pharmacological efficacy that is involved in investigating MDR in chemotherapeutic cancer strategy. Using the concrete MDR experiments, such as constructing antidrug models, the chemotherapeutic value of ferroptosis will become more practical for pharmacological explorations. Further research on specific enzymes of ferroptosis that circRNAs mediate in cancer cells needs to be addressed in the future.

In summary, although regulatory ncRNA, especially circRNAs, are complex and interactions with ferroptosis will require considerable work to unravel, circRNAs can be considered dependable diagnostic and therapeutic molecular

\section{REFERENCES}

Aishanjiang, K., Wei, X. D., Fu, Y., Lin, X., Ma, Y., Le, J., et al. (2021). Circular RNAs and hepatocellular carcinoma: new epigenetic players with diagnostic and prognostic Rroles. Front. Oncol. 11:653717. doi: 10.3389/fonc.2021.65 3717

Akdemir, B., Nakajima, Y., Inazawa, J., and Inoue, J. (2017). miR-432 Induces NRF2 stabilization by directly targeting KEAP1. Mol. Cancer Res. 15, 1570-1578. doi: 10.1158/1541-7786.MCR-17-0232

Anastasiadou, E., Jacob, L. S., and Slack, F. J. (2018). Non-coding RNA networks in cancer. Nat. Rev. Cancer 18, 5-18. doi: 10.1038/nrc.2017.99

Asma, V., Zahra, S., Ahmad, M., Soheila, M., Sima, F., Hamid, R. M., et al. (2019). Long non-coding RNAs as epigenetic regulators in cancer. Curr. Pharm. Des. 25, 3563-3577. doi: 10.2174/1381612825666190830161528

Augustin, Y., Staines, H. M., and Krishna, S. (2020). Artemisinins as a novel anti-cancer therapy: targeting a global cancer pandemic through drug repurposing. Pharmacol. Ther. 216:107706. doi: 10.1016/j.pharmthera.2020.10 7706

Bahn, J. H., Zhang, Q., Li, F., Chan, T. M., Lin, X., Kim, Y., et al. (2015). The landscape of microRNA, Piwi-interacting RNA, and circular RNA biomarkers for cancer in manipulation of cell death. They also facilitate the development of chemoresistance to anticancer drugs and provide a genetic approach for better diagnosis, predicting prognosis and treatment response to cancer.

\section{AUTHOR CONTRIBUTIONS}

KQZ and YZ had the idea for the article. BSW, LG, and WHR collected the references, performed the literature search, and data analysis. YZ and KXL drafted the first manuscript and prepared the figures and tables. KQZ and KXL designed and corrected the final manuscript. All authors contributed to the study conception and design and read and approved the final manuscript.

\section{FUNDING}

KQZ was supported by the National Natural Science Foundation of China (Nos. 81502354 and 81600880), Natural Science Foundation of Shandong Province (Nos. 2019GSF108273, 2017WS215, and ZR2018BH021), Source Innovation Planning of Qingdao (Nos. 18-2-2-77-jch and 196-1-35-nsh), Qingdao/China Postdoctoral Science Foundation (Nos. 2017M622145 and 2017M612217), Shandong Government sponsored Study Abroad Program Scholarship, and Qingdao Outstanding Health Professional Development Fund. YZ was funded through the College Undergraduate Training Program for Innovation and Entrepreneurship of Central South University (No. 20190029020012).

\section{ACKNOWLEDGMENTS}

We would like to thank Zhaojian Gong and Zhangui Tang for helpful comments on this manuscript. We acknowledge support from the Department of Oral and Maxillofacial, the Second Xiangya Hospital of Central South University, Changsha, Hunan.

in human saliva. Clin. Chem. 61, 221-230. doi: 10.1373/clinchem.2014.23 0433

Bai, T., Liang, R., Zhu, R., Wang, W., Zhou, L., and Sun, Y. (2020). MicroRNA214-3p enhances erastin-induced ferroptosis by targeting ATF4 in hepatoma cells. J. Cell. Physiol. 235, 5637-5648. doi: 10.1002/jcp.29496

Bannai, S., and Tateishi, N. (1986). Role of membrane transport in metabolism and function of glutathione in mammals. J. Membr. Biol. 89, 1-8. doi: 10.1007/ BF01870891

Bao, W. D., Zhou, X. T., Zhou, L. T., Wang, F., Yin, X., Lu, Y., et al. (2020). Targeting miR-124/Ferroportin signaling ameliorated neuronal cell death through inhibiting apoptosis and ferroptosis in aged intracerebral hemorrhage murine model. Aging Cell 19:e13235. doi: 10.1111/acel. 13235

Bridges, R. J., Natale, N. R., and Patel, S. A. (2012). System xc(-) cystine/glutamate antiporter: an update on molecular pharmacology and roles within the CNS. Br. J. Pharmacol. 165, 20-34. doi: 10.1111/j.1476-5381.2011.01480.x

Chen, C., Jiang, X., Gu, S., and Zhang, Z. (2017). MicroRNA-155 regulates arseniteinduced malignant transformation by targeting Nrf2-mediated oxidative damage in human bronchial epithelial cells. Toxicol. Lett. 278, 38-47. doi: 10.1016/j.toxlet.2017.07.215 
Chen, G., Li, Y., He, Y., Zeng, B., Yi, C., Wang, C., et al. (2020). Upregulation of circular RNA circATRNL1 to sensitize oral squamous cell carcinoma to irradiation. Mol. Ther. Nucleic Acids 19, 961-973. doi: 10.1016/j.omtn.2019.12. 031

Chen, G. Q., Benthani, F. A., Wu, J., Liang, D., Bian, Z. X., and Jiang, X. (2020). Artemisinin compounds sensitize cancer cells to ferroptosis by regulating iron homeostasis. Cell Death Differ. 27, 242-254. doi: 10.1038/s41418-019-0352-3

Chen, S., Jiao, J. W., Sun, K. X., Zong, Z. H., and Zhao, Y. (2015). MicroRNA$133 \mathrm{~b}$ targets glutathione $\mathrm{S}$-transferase pi expression to increase ovarian cancer cell sensitivity to chemotherapy drugs. Drug Des. Devel. Ther. 9, 5225-5235. doi: 10.2147/DDDT.S87526

Chen, Y. F., Wei, Y. Y., Yang, C. C., Liu, C. J., Yeh, L. Y., Chou, C. H., et al. (2019). miR-125b suppresses oral oncogenicity by targeting the anti-oxidative gene PRXL2A. Redox Biol. 22:101140. doi: 10.1016/j.redox.2019.101140

Choi, D. W. (1988). Glutamate neurotoxicity and diseases of the nervous system. Neuron 1, 623-634. doi: 10.1016/0896-6273(88)90162-6

Chu, B., Kon, N., Chen, D., Li, T., Liu, T., Jiang, L., et al. (2019). ALOX12 is required for p53-mediated tumour suppression through a distinct ferroptosis pathway. Nat. Cell Biol. 21, 579-591. doi: 10.1038/s41556-019-0305-6

Cui, M., Xiao, Z., Sun, B., Wang, Y., Zheng, M., Ye, L., et al. (2014). Involvement of cholesterol in hepatitis B virus $X$ protein-induced abnormal lipid metabolism of hepatoma cells via up-regulating miR-205-targeted ACSL4. Biochem. Biophys. Res. Commun. 445, 651-655. doi: 10.1016/j.bbrc.2014.02.068

Dayalan, N. S., Kostov, R. V., and Dinkova-Kostova, A. T. (2015). Transcription factors Hsf1 and Nrf2 engage in crosstalk for cytoprotection. Trends Pharmacol. Sci. 36, 6-14. doi: 10.1016/j.tips.2014.10.011

De Blasio, A., Di Fiore, R., Pratelli, G., Drago-Ferrante, R., Saliba, C., Baldacchino, S., et al. (2020). A loop involving NRF2, miR-29b-1-5p and AKT, regulates cell fate of MDA-MB-231 triple-negative breast cancer cells. J. Cell. Physiol. 235, 629-637. doi: 10.1002/jcp.29062

Deng, S. H., Wu, D. M., Li, L., Liu, T., Zhang, T., Li, J., et al. (2021). miR-324$3 p$ reverses cisplatin resistance by inducing GPX4-mediated ferroptosis in lung adenocarcinoma cell line A549. Biochem. Biophys. Res. Commun. 549, 54-60. doi: 10.1016/j.bbrc.2021.02.077

Dixon, S. J., Lemberg, K. M., Lamprecht, M. R., Skouta, R., Zaitsev, E. M., Gleason, C. E., et al. (2012). Ferroptosis: an iron-dependent form of nonapoptotic cell death. Cell 149, 1060-1072. doi: 10.1016/j.cell.2012.03.042

Dixon, S. J., Patel, D. N., Welsch, M., Skouta, R., Lee, E. D., Hayano, M., et al. (2014). Pharmacological inhibition of cystine-glutamate exchange induces endoplasmic reticulum stress and ferroptosis. eLife 3:e02523. doi: 10.7554/eLife. 02523

Dou, Z., Gao, L., Ren, W., Zhang, H., Wang, X., Li, S., et al. (2020a). CiRS-7 functions as a ceRNA of RAF-1/PIK3CD to promote metastatic progression of oral squamous cell carcinoma via MAPK/AKT signaling pathways. Exp. Cell. Res. 396:112290. doi: 10.1016/j.yexcr.2020.112290

Dou, Z., Li, S., Ren, W., Wang, Q., Liu, J., Kong, X., et al. (2020b). Decreased expression of hsa_circ_0072387 as a valuable predictor for oral squamous cell carcinoma. Oral Dis. 25, 1302-1308. doi: 10.1111/odi.13094

Drakesmith, H., Nemeth, E., and Ganz, T. (2015). Ironing out ferroportin. Cell Metab. 22, 777-787. doi: 10.1016/j.cmet.2015.09.006

Drayton, R. M., Dudziec, E., Peter, S., Bertz, S., Hartmann, A., Bryant, H. E., et al. (2014). Reduced expression of miRNA-27a modulates cisplatin resistance in bladder cancer by targeting the cystine/glutamate exchanger SLC7A11. Clin. Cancer Res. 20, 1990-2000. doi: 10.1158/1078-0432.CCR-132805

Du, J., Wang, T., Li, Y., Zhou, Y., Wang, X., Yu, X., et al. (2019). DHA inhibits proliferation and induces ferroptosis of leukemia cells through autophagy dependent degradation of ferritin. Free Radic. Biol. Med. 381, 165-175.

Du, W. W., Zhang, C., Yang, W., Yong, T., Awan, F. M., and Yang, B. B. (2017). Identifying and characterizing circRNA-protein interaction. Theranostics 7 , 4183-4191. doi: 10.7150/thno.21299

Frey, L., Klümper, N., Schmidt, D., Kristiansen, G., Toma, M., Ritter, M., et al. (2021). CircEHD2, CircNETO2 and CircEGLN3 as diagnostic and prognostic biomarkers for patients with renal cell carcinoma. Cancers (Basel) 13:2177. doi: $10.3390 /$ cancers 13092177

Gao, D., Zhang, X., Liu, B., Meng, D., Fang, K., Guo, Z., et al. (2017). Screening circular RNA related to chemotherapeutic resistance in breast cancer. Epigenomics 9, 1175-1188. doi: 10.2217/epi-2017-0055
Gao, L., Dou, Z. C., Ren, W. H., Li, S. M., Liang, X., and Zhi, K. Q. (2019a). CircCDR1as upregulates autophagy under hypoxia to promote tumor cell survival via AKT/ERKvimTOR signaling pathways in oral squamous cell carcinomas. Cell Death Dis. 10:745. doi: 10.1038/s41419-019-1971-9

Gao, L., Zhao, C., Li, S., Dou, Z., Wang, Q., Liu, J., et al. (2019b). Circ-PKD2 inhibits carcinogenesis via the miR-204-3p/APC2 axis in oral squamous cell carcinoma. Mol. Carcinog. 58, 1783-1794. doi: 10.1002/mc.23065

Gao, M., Li, C., Xu, M., Liu, Y., Cong, M., and Liu, S. (2018). LncRNA MT1DP aggravates cadmium-induced oxidative stress by repressing the function of Nrf2 and is dependent on interaction with miR-365. Adv. Sci. 5:1800087. doi: 10.1002/advs.201800087

Gaschler, M. M., Andia, A. A., Liu, H., Csuka, J. M., Hurlocker, B., Vaiana, C. A., et al. (2018). FINO2 initiates ferroptosis through GPX4 inactivation and iron oxidation. Nat. Chem. Biol. 14, 507-515. doi: 10.1038/s41589-018-0031-6

Geng, N., Shi, B. J., Li, S. L., Zhong, Z. Y., Li, Y. C., Xua, W. L., et al. (2018). Knockdown of ferroportin accelerates erastin-induced ferroptosis in neuroblastoma cells. Eur. Rev. Med. Pharmacol. Sci. 22, 3826-3836. doi: 10. 26355/eurrev_201806_15267

Giles, K. M., Brown, R. A., Epis, M. R., Kalinowski, F. C., and Leedman, P. J. (2013). miRNA-7-5p inhibits melanoma cell migration and invasion. Biochem. Biophys. Res. Commun. 430, 706-710. doi: 10.1016/j.bbrc.2012.11.086

Goji, T., Takahara, K., Negishi, M., and Katoh, H. (2017). Cystine uptake through the cystine/glutamate antiporter xCT triggers glioblastoma cell death under glucose deprivation. J. Biol. Chem. 292, 19721-19732. doi: 10.1074/jbc.M117. 814392

Gomaa, A., Peng, D., Chen, Z., Soutto, M., Abouelezz, K., Corvalan, A., et al. (2019). Epigenetic regulation of AURKA by miR-4715-3p in upper gastrointestinal cancers. Sci. Rep. 9:16970. doi: 10.1038/s41598-019-53174-6

Gout, P. W., Buckley, A. R., Simms, C. R., and Bruchovsky, N. (2001). Sulfasalazine, a potent suppressor of lymphoma growth by inhibition of the xI- cystine transporter: a new action for an old drug. Leukemia 15, 1633-1640. doi: 10. 1038/sj.leu.2402238

Gu, S., Lai, Y., Chen, H., Liu, Y., and Zhang, Z. (2017). miR-155 mediates arsenic trioxide resistance by activating Nrf2 and suppressing apoptosis in lung cancer cells. Sci. Rep. 7:12155. doi: 10.1038/s41598-017-06061-x

Guo, J., Xu, B., Han, Q., Zhou, H., Xia, Y., Gong, C., et al. (2018). Ferroptosis: a novel anti-tumor action for cisplatin. Cancer Res. Treat. 50, 445-460. doi: $10.4143 /$ crt.2016.572

Guo, J. U., Agarwal, V., Guo, H., and Bartel, D. P. (2014). Expanded identification and characterization of mammalian circular RNAs. Genome Biol. 15:409. doi: 10.1186/s13059-014-0409-z

Hansen, T. B., Jensen, T. I., Clausen, B. H., Bramsen, J. B., Finsen, B., Damgaard, C. K., et al. (2013). Natural RNA circles function as efficient microRNA sponges. Nature 495, 384-388. doi: 10.1038/nature11993

Javid, S. N., Layla, S., Seyed, A. A., Mohammad, S. E., Hamid, R. M., Hossein, B. B., et al. (2021). Cell death pathways and viruses: role of microRNAs. Mol. Ther. Nucleic Acids 24, 487-511. doi: 10.1016/j.omtn.2021.03.011

Jiang, T., Xia, Y., Lv, J., Li, B., Li, Y., Wang, S., et al. (2021). A novel protein encoded by circMAPK1 inhibits progression of gastric cancer by suppressing activation of MAPK signaling. Mol. Cancer 20:66. doi: 10.1186/s12943-021-01358-y

Johnsson, P., Lipovich, L., Grander, D., and Morris, K. V. (2014). Evolutionary conservation of long non-coding RNAs; sequence, structure, function. Biochim. Biophys. Acta 1840, 1063-1071. doi: 10.1016/j.bbagen.2013.10.035

Jung, K. A., Lee, S., and Kwak, M. K. (2017). NFE2L2/NRF2 activity is linked to mitochondria and amp-activated protein kinase signaling in cancers through mir-181c/mitochondria-encoded cytochrome c oxidase regulation. Antioxid. Redox Signal. 27, 945-961. doi: 10.1089/ars.2016.6797

Kobayashi, M., and Yamamoto, M. (2006). Nrf2-Keap1 regulation of cellular defense mechanisms against electrophiles and reactive oxygen species. $A d v$. Enzyme Regul. 46, 113-140. doi: 10.1016/j.advenzreg.2006.01.007

Legnini, I., Di Timoteo, G., Rossi, F., Morlando, M., Briganti, F., Sthandier, O., et al. (2017). Circ-ZNF609 is a circular RNA that can be translated and functions in myogenesis. Mol. Cell $<$ refvol>66, 22-37.e29. doi: 10.1016/j.molcel.2017.02. 017

Li, C., Tian, Y., Liang, Y., and Li, Q. (2020). Circ_0008035 contributes to cell proliferation and inhibits apoptosis and ferroptosis in gastric cancer via miR-599/EIF4A1 axis. Cancer Cell Int. 20:84. doi: 10.1186/s12935-020-01 $168-0$ 
Li, F., Zhang, L., Li, W., Deng, J., Zheng, J., An, M., et al. (2015). Circular RNA ITCH has inhibitory effect on ESCC by suppressing the Wnt/beta-catenin pathway. Oncotarget 6, 6001-6013. doi: 10.18632/oncotarget.3469

Li, M., Gao, K., Chu, L., Zheng, J., and Yang, J. (2018). The role of Aurora-A in cancer stem cells. Int. J. Biochem. Cell Biol. 98, 89-92. doi: 10.1016/j.biocel.2018. 03.007

Li, Z. J., Dai, H. Q., Huang, X. W., Feng, J., Deng, J. H., Wang, Z. X., et al. (2021). Artesunate synergizes with sorafenib to induce ferroptosis in hepatocellular carcinoma. Acta Pharmacol. Sin. 42, 301-310. doi: 10.1038/s41401-020-0478-3

Lin, R., Zhang, Z., Chen, L., Zhou, Y., Zou, P., Feng, C., et al. (2016). Dihydroartemisinin (DHA) induces ferroptosis and causes cell cycle arrest in head and neck carcinoma cells. Cancer Lett. 381, 165-175. doi: 10.1016/j.canlet. 2016.07.033

Liu, M., Hu, C., Xu, Q., Chen, L., Ma, K., Xu, N., et al. (2015). Methylseleninic acid activates Keap1/Nrf2 pathway via up-regulating miR-200a in human oesophageal squamous cell carcinoma cells. Biosci. Rep. 35:e00256. doi: 10.1042/ BSR20150092

Liu, N., Lin, X., and Huang, C. (2020). Activation of the reverse trans-sulfuration pathway through NRF2/CBS confers erastin-induced ferroptosis resistance. $B r$. J. Cancer 122, 279-292. doi: 10.1038/s41416-019-0660-X

Liu, X. X., Li, X. J., Zhang, B., Liang, Y. J., Zhou, C. X., Cao, D. X., et al. (2011). MicroRNA-26b is underexpressed in human breast cancer and induces cell apoptosis by targeting SLC7A11. FEBS Lett. 585, 1363-1367. doi: 10.1016/j. febslet.2011.04.018

Liu, Z., Wang, Q., Wang, X., Xu, Z., Wei, X., and Li, J. (2020). Circular RNA cIARS regulates ferroptosis in HCC cells through interacting with RNA binding protein ALKBH5. Cell Death Discov. 6:72. doi: 10.1038/s41420-020-00306-x

Luo, M., Wu, L., Zhang, K., Wang, H., Zhang, T., Gutierrez, L., et al. (2018). miR-137 regulates ferroptosis by targeting glutamine transporter SLC1A5 in melanoma. Cell Death Differ. 25, 1457-1472. doi: 10.1038/s41418-017-0053-8

Ma, L. L., Liang, L., Zhou, D., and Wang, S. W. (2021). Tumor suppressor miR-424$5 \mathrm{p}$ abrogates ferroptosis in ovarian cancer through targeting ACSL4. Neoplasma 7:200707N705. doi: 10.4149/neo_2020_200707N705

Ma, S., Henson, E. S., Chen, Y., and Gibson, S. B. (2016). Ferroptosis is induced following siramesine and lapatinib treatment of breast cancer cells. Cell Death Dis. 7:e2307. doi: 10.1038/cddis.2016.208

Maciel-Dominguez, A., Swan, D., Ford, D., and Hesketh, J. (2013). Selenium alters miRNA profile in an intestinal cell line: evidence that miR-185 regulates expression of GPX2 and SEPSH2. Mol. Nutr. Food Res. 57, 2195-2205. doi: 10.1002/mnfr.201300168

Mancias, J. D., Wang, X., Gygi, S. P., Harper, J. W., and Kimmelman, A. C. (2014). Quantitative proteomics identifies NCOA4 as the cargo receptor mediating ferritinophagy. Nature 509, 105-109. doi: 10.1038/nature13148

Maryam, H., Homa, B., Samaneh, M., Vida, T., Zahra, N., Mina, R. B., et al. (2021). Exosomal microRNAs and exosomal long non-coding RNAs in gynecologic cancers. Gynecol. Oncol. 161, 314-327. doi: 10.1016/j.ygyno.2021.02.004

Memczak, S., Jens, M., Elefsinioti, A., Torti, F., Krueger, J., Rybak, A., et al. (2013). Circular RNAs are a large class of animal RNAs with regulatory potency. Nature 495, 333-338. doi: 10.1038/nature11928

Miri, D., Schraga, S., Sarit, E., and Rotem, S. (2012). Transcriptome-wide discovery of circular RNAs in Archaea. Nucleic Acids Res. 40, 3131-3142. doi: 10.1093/ nar/gkr1009

Mou, Y., Wang, J., Wu, J., He, D., Zhang, C., Duan, C., et al. (2019). Ferroptosis, a new form of cell death: opportunities and challenges in cancer. J. Hematol. Oncol. 12:34. doi: 10.1186/s13045-019-0720-y

Murphy, T. H., Miyamoto, M., Sastre, A., Schnaar, R. L., and Coyle, J. T. (1989). Glutamate toxicity in a neuronal cell line involves inhibition of cystine transport leading to oxidative stress. Neuron 2, 1547-1558. doi: 10.1016/0896-6273(89) 90043-3

Neda, R., Zahra, S. R., Fatemeh, A., Amir, M. M., Haleh, P., Mohammad, K. S., et al. (2021). Non-coding RNAs related to angiogenesis in gynecological cancer. Gynecol. Oncol. S0090-8258, 258-254. doi: 10.1016/j.ygyno.2021.03.020

Nigita, G., Marceca, G. P., Tomasello, L., Distefano, R., Calore, F., Veneziano, D., et al. (2019). ncRNA editing: functional characterization and computational resources. Methods Mol. Biol. 1912, 133-174. doi: doi:10.1007/978-1-49398982-9_6
Niu, Y., Zhang, J., Tong, Y., Li, J., and Liu, B. (2019). Physcion 8-O-betaglucopyranoside induced ferroptosis via regulating miR-103a-3p/GLS2 axis in gastric cancer. Life Sci. 237:116893. doi: 10.1016/j.lfs.2019.116893

Palazzo, A. F., and Lee, E. S. (2015). Non-coding RNA: what is functional and what is junk? Front. Genet. 6:2. doi: 10.3389/fgene.2015.00002

Peng, L., Chen, G., Zhu, Z., Shen, Z., Du, C., Zang, R., et al. (2017). Circular RNA ZNF609 functions as a competitive endogenous RNA to regulate AKT3 expression by sponging miR-150-5p in Hirschsprung's disease. Oncotarget 8 , 808-818. doi: 10.18632/oncotarget.13656

Qu, J., Zhang, L., Li, L., and Su, Y. (2018). miR-148b functions as a tumor suppressor by targeting endoplasmic reticulum metallo protease 1 in human endometrial cancer cells. Oncol. Res. 27, 81-88. doi: 10.3727/ $096504018 X 15202988139874$

Robinson, J. L., McBreairty, L. E., Randell, E. W., Harding, S. V., Bartlett, R. K., Brunton, J. A., et al. (2018). Betaine or folate can equally furnish remethylation to methionine and increase transmethylation in methioninerestricted neonates. J. Nutr. Biochem. 59, 129-135. doi: 10.1016/j.jnutbio.2018. 06.001

Roh, J. L., Kim, E. H., Jang, H., and Shin, D. (2017). Nrf2 inhibition reverses the resistance of cisplatin-resistant head and neck cancer cells to artesunateinduced ferroptosis. Redox Biol. 11, 254-262. doi: 10.1016/j.redox.2016.12.010

Rupaimoole, R., and Slack, F. J. (2017). MicroRNA therapeutics: towards a new era for the management of cancer and other diseases. Nat. Rev. Drug. Discov. 16, 203-222. doi: 10.1038/nrd.2016.246

Salzman, J., Chen, R. E., Olsen, M. N., Wang, P. L., and Brown, P. O. (2013). Cell-type specific features of circular RNA expression. PLoS Genet. 9:e1003777. doi: 10.1371/journal.pgen.1003777

Sengupta, D., Cassel, T., Teng, K. Y., Aljuhani, M., Chowdhary, V. K., Hu, P., et al. (2020). Regulation of hepatic glutamine metabolism by miR-122. Mol. Metab. 34, 174-186. doi: 10.1016/j.molmet.2020.01.003

Seyed, M. H., Mohammad, H. P., Sara, F., Ali, A. V., Hamed, M., and Michael, R. H. (2020). Non-coding RNAs and Exosomes: their role in the pathogenesis of sepsis. Mol. Ther. Nucleic Acids 21, 51-74. doi: 10.1016/j.omtn.2020.05.012

Shi, L., Chen, Z. G., Wu, L. L., Zheng, J. J., Yang, J. R., Chen, X. F., et al. (2014). miR-340 reverses cisplatin resistance of hepatocellular carcinoma cell lines by targeting Nrf2-dependent antioxidant pathway. Asian Pac. J. Cancer Prev. 15, 10439-10444. doi: 10.7314/apjcp.2014.15.23.10439

Shimada, K., Skouta, R., Kaplan, A., Yang, W. S., Hayano, M., Dixon, S. J., et al. (2016). Global survey of cell death mechanisms reveals metabolic regulation of ferroptosis. Nat. Chem. Biol. 12, 497-503. doi: 10.1038/nchembio.2079

Shin, D., Kim, E. H., Lee, J., and Roh, J. L. (2018). Nrf2 inhibition reverses resistance to GPX4 inhibitor-induced ferroptosis in head and neck cancer. Free Radic. Biol. Med. 129, 454-462. doi: 10.1016/j.freeradbiomed.2018.10.426

Singh, B., Ronghe, A. M., Chatterjee, A., Bhat, N. K., and Bhat, H. K. (2013). MicroRNA-93 regulates NRF2 expression and is associated with breast carcinogenesis. Carcinogenesis 34, 1165-1172. doi: 10.1093/carcin/bgt026

Skrzypek, K., Tertil, M., Golda, S., Ciesla, M., Weglarczyk, K., Collet, G., et al. (2013). Interplay between heme oxygenase-1 and miR-378 affects non-small cell lung carcinoma growth, vascularization, and metastasis. Antioxid. Redox Signal. 19, 644-660. doi: 10.1089/ars.2013.5184

Slack, F. J., and Chinnaiyan, A. M. (2019). The role of non-coding RNAs in oncology. Cell 179, 1033-1055. doi: 10.1016/j.cell.2019.10.017

Song, Z., Jia, G., Ma, P., and Cang, S. (2021). Exosomal miR-4443 promotes cisplatin resistance in non-small cell lung carcinoma by regulating FSP1 m6A modification-mediated ferroptosis. Life Sci. 276:119399. doi: 10.1016/j.lfs.2021. 119399

Stockwell, B. R., Friedmann Angeli, J. P., Bayir, H., Bush, A. I., Conrad, M., Dixon, S. J., et al. (2017). Ferroptosis: a regulated cell death nexus linking metabolism. Cell 171, 273-285. doi: 10.1016/j.cell.2017.09.021

Sun, W. Y., Tyurin, V. A., Mikulska-Ruminska, K., Shrivastava, I. H., Anthonymuthu, T. S., Zhai, Y. J., et al. (2021). Phospholipase iPLA2 $\beta$ averts ferroptosis by eliminating a redox lipid death signal. Nat. Chem. Biol. 17, 465-476. doi: 10.1038/s41589-020-00734-X

Sun, X., Liu, D., Xue, Y., and Hu, X. (2017). Enforced miR-144-3p expression as a non-invasive biomarker for the acute myeloid leukemia patients mainly by yargeting NRF2. Clin. Lab. 63, 679-687. doi: 10.7754/Clin.Lab.2016.161116 
Sun, X., Niu, X., Chen, R., He, W., Chen, D., Kang, R., et al. (2016). Metallothionein-1G facilitates sorafenib resistance through inhibition of ferroptosis. Hepatology 64, 488-500. doi: 10.1002/hep.28574

Tomita, K., Fukumoto, M., Itoh, K., Kuwahara, Y., Igarashi, K., Nagasawa, T., et al. (2019). MiR-7-5p is a key factor that controls radioresistance via intracellular $\mathrm{Fe}(2+)$ content in clinically relevant radioresistant cells. Biochem. Biophys. Res. Commun. 518, 712-718. doi: 10.1016/j.bbrc.2019.08.117

van Jaarsveld, M. T., Helleman, J., Boersma, A. W., van Kuijk, P. F., van Ijcken, W. F., Despierre, E., et al. (2013). miR-141 regulates KEAP1 and modulates cisplatin sensitivity in ovarian cancer cells. Oncogene 32, 4284-4293. doi: 10. 1038/onc.2012.433

Verduci, L., Tarcitano, E., Strano, S., Yarden, Y., and Blandino, G. (2020). CircRNAs: role in human diseases and potential use as biomarkers. Cell Death Dis. 12:468. doi: 10.1038/s41419-021-03743-3

Wang, J., Wang, B., Ren, H., and Chen, W. (2019). miR-9-5p inhibits pancreatic cancer cell proliferation, invasion and glutamine metabolism by targeting GOT1. Biochem. Biophys. Res. Commun. 509, 241-248. doi: 10.1016/j.bbrc.2018. 12.114

Wang, K., Long, B., Liu, F., Wang, J. X., Liu, C. Y., Zhao, B., et al. (2016). A circular RNA protects the heart from pathological hypertrophy and heart failure by targeting miR-223. Eur. Heart J. 37, 2602-2611. doi: 10.1093/eurheartj/ehv713

Wang, M., Mao, C., Ouyang, L., Liu, Y., Lai, W., Liu, N., et al. (2019). Long noncoding RNA LINC00336 inhibits ferroptosis in lung cancer by functioning as a competing endogenous RNA. Cell Death Differ. 26, 2329-2343. doi: 10. 1038/s41418-019-0304-y

Wang, N., Zhang, L., Lu, Y., Zhang, M., Zhang, Z., Wang, K., et al. (2017). Down-regulation of microRNA-142-5p attenuates oxygen-glucose deprivation and reoxygenation-induced neuron injury through up-regulating Nrf2/ARE signaling pathway. Biomed. Pharmacother. 89, 1187-1195. doi: 10.1016/j. biopha.2017.03.011

Wang, P. L., Bao, Y., Yee, M. C., Barrett, S. P., Hogan, G. J., Olsen, M. N., et al. (2014). Circular RNA is expressed across the eukaryotic tree of life. PLoS One 9:e90859. doi: 10.1371/journal.pone.0090859

Wang, X., Zhang, H., Yang, H., Bai, M., Ning, T., Deng, T., et al. (2020). Exosomedelivered circRNA promotes glycolysis to induce chemoresistance through the miR-122-PKM2 axis in colorectal cancer. Mon. Oncol. 14, 539-555. doi: 10. 1002/1878-0261.12629

Wang, Y., Mo, Y., Gong, Z., Yang, X., Yang, M., Zhang, S., et al. (2017). Circular RNAs in human cancer. Mol. Cancer 16, 25. doi: 10.1186/s12943-017-0598-7

Wang, Y., Chen, H., and Wei, X. (2021). Circ_0007142 downregulates miR-8743p-mediated GDPD5 on colorectal cancer cells. Eur. J. Clin. Invest. 2:e13541.

Ward, R. J., Zucca, F. A., Duyn, J. H., Crichton, R. R., and Zecca, L. (2014). The role of iron in brain ageing and neurodegenerative disorders. Lancet Neurol. 13, 1045-1060. doi: 10.1016/S1474-4422(14)70117-6

Wei, Y., Lu, C., Zhou, P., Zhao, L., Lyu, X., Yin, J., et al. (2021). EIF4A3-induced circular RNA ASAP1 promotes tumorigenesis and temozolomide resistance of glioblastoma via NRAS/MEK1/ERK1-2 signaling. Neuro. Oncol. 23, 611-624. doi: $10.1093 /$ neuonc/noaa214

Wu, P., Li, C., Ye, D. M., Yu, K., Li, Y., Tang, H., et al. (2021). Circular RNA circEPSTI1 accelerates cervical cancer progression via miR-375/409-3P/515-5pSLC7A11 axis. Aging 13, 4663-4673. doi: 10.18632/aging.202518

Wu, Y., Sun, X., Song, B., Qiu, X., and Zhao, J. (2017). MiR-375/SLC7A11 axis regulates oral squamous cell carcinoma proliferation and invasion. Cancer Med. 6, 1686-1697. doi: 10.1002/cam4.1110

Xia, S., Feng, J., Lei, L., Hu, J., Xia, L., Wang, J., et al. (2017). Comprehensive characterization of tissue-specific circular RNAs in the human and mouse genomes. Brief Bioinform. 18, 984-992. doi: 10.1093/bib/bbw081

Xiao, F. J., Zhang, D., Wu, Y., Jia, Q. H., Zhang, L., Li, Y. X., et al. (2019). miRNA17-92 protects endothelial cells from erastin-induced ferroptosis through targeting the A20-ACSL4 axis. Biochem. Biophys. Res. Commun. 515, 448-454. doi: 10.1016/j.bbrc.2019.05.147

Xie, Y., Hou, W., Song, X., Yu, Y., Huang, J., Sun, X., et al. (2016). Ferroptosis: process and function. Cell Death Differ. 23, 369-379. doi: 10.1038/cdd.2015.158

Xu, Q., Zhou, L., Yang, G., Meng, F., Wan, Y., Wang, L., et al. (2020). CircIL4R facilitates the tumorigenesis and inhibits ferroptosis in hepatocellular carcinoma by regulating the miR-541-3p/GPX4 axis. Cell Biol. Int. 44, 23442356.
Yagoda, N., von Rechenberg, M., Zaganjor, E., Bauer, A. J., Yang, W. S., Fridman, D. J., et al. (2007). RAS-RAF-MEK-dependent oxidative cell death involving voltage-dependent anion channels. Nature 447, 864-868. doi: 10. 1038/nature05859

Yamamoto, S., Inoue, J., Kawano, T., Kozaki, K., Omura, K., and Inazawa, J. (2014). The impact of miRNA-based molecular diagnostics and treatment of NRF2stabilized tumors. Mol. Cancer Res. 12, 58-68. doi: 10.1158/1541-7786.MCR13-0246- T

Yang, H., Xiang, S., Kazi, A., and Sebti, S. M. (2020). The GTPase KRAS suppresses the p53 tumor suppressor by activating the NRF2-regulated antioxidant defense system in cancer cells. J. Biol. Chem. 295, 3055-3063. doi: 10.1074/jbc.RA119. 011930

Yang, M., Yao, Y., Eades, G., Zhang, Y., and Zhou, Q. (2011). MiR-28 regulates Nrf2 expression through a Keap1-independent mechanism. Breast Cancer Res. Treat. 129, 983-991. doi: 10.1007/s10549-011-1604-1

Yang, W. S., SriRamaratnam, R., Welsch, M. E., Shimada, K., Skouta, R., Viswanathan, V. S., et al. (2014). Regulation of ferroptotic cancer cell death by GPX4. Cell 156, 317-331. doi: 10.1016/j.cell.2013.12.010

Yang, W. S., and Stockwell, B. R. (2008). Synthetic lethal screening identifies compounds activating iron-dependent, nonapoptotic cell death in oncogenicRAS-harboring cancer cells. Chem. Biol. 15, 234-245. doi: 10.1016/j.chembiol. 2008.02.010

Yuan, W., Zhou, R., Wang, J., Han, J., Yang, X., Yu, H., et al. (2019). Circular RNA Cdrlas sensitizes bladder cancer to cisplatin by upregulating APAF1 expression through miR-1270 inhibition. Mol. Oncol. 13, 1559-1576. doi: 10.1002/18780261.12523

Zahra, S. R., Vida, T., Shahab, M., Maryam, G., Hamid, R. M., Neda, R., et al. (2021). Gynecologic cancers and non-coding RNAs: epigenetic regulators with emerging roles. Crit. Rev. Oncol. Hematol. 157:103192. doi: 10.1016/j. critrevonc.2020.103192

Zeng, Y., Du, W. W., Wu, Y., Yang, Z., Awan, F. M., Li, X., et al. (2017). A circular RNA binds to and activates AKT phosphorylation and nuclear localization reducing apoptosis and enhancing cardiac repair. Theranostics 7, 3842-3855. doi: 10.7150/thno.19764

Zhang, H., Deng, T., Liu, R., Ning, T., Yang, H., Liu, D., et al. (2020). CAF secreted miR-522 suppresses ferroptosis and promotes acquired chemoresistance in gastric cancer. Mol. Cancer 19:43. doi: 10.1186/s12943-02001168-8

Zhang, H., Ge, Z., Wang, Z., Gao, Y., Wang, Y., and Qu, X. (2021a). Circular RNA RHOT1 promotes progression and inhibits ferroptosis via mir-106a5p/STAT3 axis in breast cancer. Aging 13, 8115-8126. doi: 10.18632/aging.20 2608

Zhang, H., Xiao, X., Wei, W., Huang, C., Wang, M., Wang, L., et al. (2021b). CircLIFR synergizes with MSH2 to attenuate chemoresistance via MutS $\alpha /$ ATMp73 axis in bladder cancer. Mol. Cancer 20:70. doi: 10.1186/s12943-02101360-4

Zhang, H. Y., Zhang, B. W., Zhang, Z. B., and Deng, Q. J. (2020). Circular RNA TTBK2 regulates cell proliferation, invasion and ferroptosis via miR-761/ITGB8 axis in glioma. Eur. Rev. Med. Pharmacol. Sci. 24, 2585-2600. doi: 10.26355/ eurrev_202003_20528

Zhang, K., Wu, L., Zhang, P., Luo, M., Du, J., Gao, T., et al. (2018). miR-9 regulates ferroptosis by targeting glutamic-oxaloacetic transaminase GOT1 in melanoma. Mol. Carcinog. 57, 1566-1576. doi: 10.1002/mc.22878

Zhang, N., Gao, L., Ren, W., Li, S., Zhang, D., Song, X., et al. (2020). Fucoidan affects oral squamous cell carcinoma cell functions in vitro by regulating FLNAderived circular RNA. Ann. N. Y. Acad Sci. 1462, 65-78. doi: 10.1111/nyas. 14190

Zhang, W., Guo, J., Gao, L., Ren, W., Li, S. M., Zheng, J., et al. (2021c). Upregulation of $\mathrm{mmu}$ _circ_0001066 attenuates the inhibitory effect of bisphosphonates on osteoclastogenesis. Oral Dis. 1-12. doi: 10.1111/odi. 13871

Zheng, J., Zhu, X., He, Y., Hou, S., Liu, T., Zhi, K., et al. (2021). CircCDK8 regulates osteogenic differentiation and apoptosis of PDLSCs by inducing ER stress/autophagy during hypoxia. Ann. N. Y. Acad Sci. 1485, 56-70. doi: 10. 1111/nyas. 14483

Zheng, Q., Bao, C., Guo, W., Li, S., Chen, J., Chen, B., et al. (2016). Circular RNA profiling reveals an abundant circHIPK3 that regulates cell growth by 
sponging multiple miRNAs. Nat. Commun. 7:11215. doi: 10.1038/ncomms 11215

Zhong, Y., Du, Y., Yang, X., Mo, Y., Fan, C., Xiong, F., et al. (2018). Circular RNAs function as ceRNAs to regulate and control human cancer progression. Mol. Cancer 17, 79. doi: 10.1186/s12943-018-0827-8

Zhou, S., Ye, W., Zhang, Y., Yu, D., Shao, Q., Liang, J., et al. (2016). miR-144 reverses chemoresistance of hepatocellular carcinoma cell lines by targeting Nrf2-dependent antioxidant pathway. Am. J. Transl. Res. 8, 2992-3002.

Zuo, S., Yu, J., Pan, H., and Lu, L. (2020). Novel insights on targeting ferroptosis in cancer therapy. Biomark. Res. 8:50. doi: 10.1186/s40364-020-00229-w
Conflict of Interest: The authors declare that the research was conducted in the absence of any commercial or financial relationships that could be construed as a potential conflict of interest.

Copyright $\odot 2021$ Zhi, Gao, Wang, Ren, Liang and Zhi. This is an open-access article distributed under the terms of the Creative Commons Attribution License (CC BY). The use, distribution or reproduction in other forums is permitted, provided the original author(s) and the copyright owner(s) are credited and that the original publication in this journal is cited, in accordance with accepted academic practice. No use, distribution or reproduction is permitted which does not comply with these terms. 